\title{
Transcription levels and prognostic significance of the NFI family members in human cancers
}

\author{
Yuexian Li ${ }^{1}$, Cheng Sun ${ }^{1}$, Yonggang Tan ${ }^{1}$, Lin Li $^{2}$, Heying Zhang ${ }^{1}$, Yusi Liang ${ }^{1}$, Juan Zeng ${ }^{1}$, Huawei Zou ${ }^{\text {Corresp. } 1}$ \\ ${ }^{1}$ The First Oncology Department, Shengjing Hospital affiliated with China Medical University, shenyang, China \\ 2 The First Oncology Department, The Fourth Hospital affiliated with China Medical University, shenyang, China \\ Corresponding Author: Huawei Zou \\ Email address: Zouhw999@163.com
}

Background: The nuclear factor I (NFI) is a family of transcription factors consisting of four distinct but closely related genes, NFIA, NFIB, NFIC, and NFIX, which are important in the development of various tissues and organs in mammals. Recent study results have shown that NFI family may play a critical role in the progression of various human tumors and have been identified as key tumor suppressors and oncogenes for many cancers. However, the expression levels and distinctive prognostic values of the NFI family remain poorly explored in most cancers.

Materials and Methods: In the present study, the differences in mRNA expression of the NFI family in various cancers were investigated using the Oncomine and TCGA databases, and the mRNA expression, genetic alteration, and DNA methylation of the NFI family members in various cancers were examined using cBioPortal for Cancer Genomics. In addition, the prognostic significance of the NFI family was assessed in multiple cancers using the Kaplan-Meier plotter (KM plotter) and SurvExpress databases.

Results: The mRNA expression levels in the NFI family were significantly downregulated in most cancers compared with normal tissues and DNA hypermethylation might downregulate the NFI family expression. Although NFIX expression was not downregulated in kidney, colorectal, and prostate cancers.

Furthermore, NFIB expression was upregulated in gastric cancer. Further survival analyses based on the KM plotter and SurvExpress databases showed dysregulations of the NFI genes were significantly correlated with survival outcomes in breast, lung, and head and neck cancers. Decreased expression levels of NFIA, NFIB, and NFIC were associated with poor overall survival (OS) in head and neck cancer. Low mRNA expression of NFIA and NFIB was significantly associated with OS and first progression (FP) in lung adenocarcinoma, but not in lung squamous cell carcinoma. In addition, potential correlations between NFI family members and survival outcomes were also observed in liver, esophageal, kidney, and cervical cancer.

Conclusion: The results from the present study indicated certain members of the NFI family could be promising therapeutic targets and novel prognostic biomarkers for human cancers. 
1 ORIGINAL RESEARCH

\section{Transcription levels and prognostic significance of the NFI}

\section{3 family members in human cancers}

4

5 Yuexian $\mathrm{Li}^{1}$, Cheng Sun ${ }^{1}$, Yonggang Tan ${ }^{1}$, Lin $\mathrm{Li}^{2}$, Heying Zhang ${ }^{1}$, Yusi Liang ${ }^{1}$, Juan Zeng ${ }^{1}$ and Huawei

6 Zou $^{1}$

$7 \quad{ }^{1}$ The First Oncology Department, Shengjing Hospital affiliated with China Medical University, Shenyang

8 110004, China; ${ }^{2}$ The First Oncology Department, The Fourth Hospital affiliated with China Medical

9 University, Shenyang 110032, China.

Correspondence: Huawei Zou

The First Oncology Department, Shengjing Hospital affiliated with China Medical University, Shenyang

110004, China

Tel +8613322470880

\section{Email Zouhw999@163.com}

Background: The nuclear factor I (NFI) is a family of transcription factors consisting of four distinct but closely related genes, NFIA, NFIB, NFIC, and NFIX, which are important in the development of various tissues and organs in mammals. Recent study results have shown that NFI family may play a critical role 
oncogenes for many cancers. However, the expression levels and distinctive prognostic values of the NFI family remain poorly explored in most cancers.

Materials and Methods: In the present study, the differences in mRNA expression of the NFI family in various cancers were investigated using the Oncomine and TCGA databases, and the mRNA expression, genetic alteration, and DNA methylation of the NFI family members in various cancers were examined using cBioPortal for Cancer Genomics. In addition, the prognostic significance of the NFI family was assessed in multiple cancers using the Kaplan-Meier plotter (KM plotter) and SurvExpress databases.

Results: The mRNA expression levels in the NFI family were significantly downregulated in most cancers compared with normal tissues and DNA hypermethylation might downregulate the NFI family expression. Although NFIX expression was not downregulated in kidney, colorectal, and prostate cancers. Furthermore, NFIB expression was upregulated in gastric cancer. Further survival analyses based on the KM plotter and SurvExpress databases showed dysregulations of the NFI genes were significantly correlated with survival outcomes in breast, lung, and head and neck cancers. Decreased expression levels of NFIA, NFIB, and NFIC were associated with poor overall survival (OS) in head and neck cancer. Low mRNA expression of NFIA and NFIB was significantly associated with OS and first progression (FP) in lung adenocarcinoma, but not in lung squamous cell carcinoma. In addition, potential correlations between NFI family members and survival outcomes were also observed in liver, esophageal, kidney, and cervical cancer.

Conclusion: The results from the present study indicated certain members of the NFI family could be promising therapeutic targets and novel prognostic biomarkers for human cancers.

Keywords: human cancers, NFI, biomarker, Oncomine, TCGA 


\section{Introduction}

42 Cancer is the leading cause of death and a major public health concern worldwide. Globally, 18.1 million

43 new cancer cases and 9.6 million cancer deaths were reported in 2018 (Bray et al. 2018). In addition to the

44 diagnostic techniques and treatments such as surgical resection, radiotherapy and new targeted

45 chemotherapies have become more advanced. However, the efficacy of cancer treatments remains

46 unsatisfactory. Thus, investigating the mechanisms of tumorigenesis and tumor progression is urgently

47 needed, as well as identifying potential biomarkers for improved diagnosis, prognosis, and treatment.

48 Nuclear factor I (NFI), or CCAAT box-binding transcription factor (CTF), was first identified as a single protein purified from human Hela cells and essential for the replication of adenovirus DNA in vitro (Nagata et al. 1982). In humans, the NFI family consists of four closely related transcription factors, NFIA, NFIB, NFIC, and NFIX that can bind as either hetero- or homodimers to a duplex consensus sequence

52 TTGGC(N5)GCCAA. These dimers have comparable affinity for DNA, stability, and specificity (Kruse \& Sippel 1994; Leegwater et al. 1985). Over the past decades, the members of NFI family have been shown to regulate cell proliferation and differentiation during the development of multiple organ systems. Emerging evidence has gradually shown NFI expression in various cancers. In addition, results from other studies indicated that NFI genes are closely related to a number of tumor suppressor or oncogene processes and disease states. Song et al. demonstrated NFIA was highly expressed in astrocytomas and associated with better progression-free survival (PFS) (Song et al. 2010). NFIB is amplified and expressed in human small cell lung cancer (SCLC) and controls cell proliferation and apoptosis (Dooley et al. 2011). Moreover, lower 
61 epithelial-mesenchymal transition (EMT), migration, and invasion (Lee et al. 2015). NFIX mRNA expression

62 was downregulated in non-SCLC (NSCLC), and reduced NFIX expression was shown to independently

63 predict poor prognosis in lung adenocarcinoma but not in squamous cell carcinoma (Ge et al. 2018). In

64 summary, the results from previous studies indicate the NFI family members participate in multiple human

65 cancers and may act as potential therapeutic targets or prognostic biomarkers in some cancers. However,

66 a systematic analysis regarding the transcriptional expression and prognostic values in human cancers is

67 lacking.

68 In the present study, the differences in mRNA expression of the NFI family members between tumors and

69 normal tissues in multiple cancers were investigated using the Oncomine and TCGA databases.

70 Furthermore, the mRNA expression, genetic alteration, and DNA methylation of the NFI family members in

71 various cancers were examined using cBioPortal for Cancer Genomics. In addition, the prognostic

72 significance of the NFI family was evaluated using the Kaplan-Meier Plotter (KM plotter) and SurvExpress

73 databases.

\section{Materials and Methods}

\section{Oncomine database}

76 Oncomine (http://www.oncomine.org), an online cancer microarray database and web-based data-mining

77 platform, was used to analyze the individual mRNA levels of NFI transcription factors between cancers and 
analysis type: cancer vs. normal analysis. Cancer type, sample size, fold change, $t$-test, and $p$-value were obtained from studies that showed statistically significant differences.

\section{TCGA analysis using UCSC Xena browser}

Integrin mRNA HiSeq expression data from the TCGA database involving breast, lung, melanoma, pancreatic, and bladder cancers, as well as other cancers, were obtained from the UCSC Xena browser (https://xenabrowser.net) version: 2017-05-06. Student's $t$-test was performed to investigate differences in the mRNA expression levels between tumors and normal tissues. The boxplots were made using the GraphPad prism software.

\section{cBioPortal for Cancer Genomics database}

The cBioPortal for Cancer Genomics (http://www.cbioportal.org/) is an open-access resource for the interactive exploration of multidimensional cancer genomics data sets. The genetic alterations in multiple cancers were examined using cBioPortal for Cancer Genomics (Cerami et al. 2012; Gao et al. 2013). The correlation between mRNA (RNA Seq V2 RSEM) and DNA methylation (HM450) in various cancers was calculated according to the cBioPortal's online instructions.

\section{KM plotter database}

The KM plotter (http://kmplot.com/analysis/) database assesses the effects of 54,675 genes on survival in 18,674 cancer types. In this database, the survival data for breast, lung, bladder, head and neck, esophageal, and kidney cancers are available (Nagy et al. 2018). In the present study, the database was used to analyze the prognostic values of NFI genes in those cancers. For each gene symbol, the desired probe IDs were individually entered into the database to obtain Kaplan-Meier plots. Patients were divided into high and low expression groups based on the median values of mRNA expression levels, and survival 
101

102

103

104

105

106

107

108

109

110

111

112

113

114

115

116

117

118

119

120

analyses were performed without follow-up restrictions. The number of cases, hazard ratios (HRs), $95 \%$

confidence intervals (Cls), and log rank p-values were extracted from the KM plotter webpage.

\section{SurvExpress database}

The SurvExpress database was used to obtain survival data for prostate cancer, for which information was not available in the KM plotter database (Aguirre-Gamboa et al. 2013). The TCGA database was used for analysis because both the desirable probes and larger sample size were present ( $>200$ patients). The hazard odds ratio with $95 \% \mathrm{Cl}$ having $p$-values $\leq 0.05$ was considered statistically significant.

\section{Results}

\section{The mRNA expression patterns of the NFI family members in human cancers}

The Oncomine database was used to analyze the mRNA expression differences of four NFI genes between tumors and normal tissues in various cancers. As shown in Figure 1, the database contained a total of 312, 449, 438, and 457 unique analyses for NFIA, NFIB, NFIC, and NFIX, respectively. In 69 studies, a statistically significant difference for NFIA was observed. In 53 of the 69 studies, 14 types of cancers showed decreased NFIA mRNA expression level compared with normal tissues; however, in 16 studies, the opposite results were observed. Ninety-three unique analyses revealed the NFIB mRNA expression level varied with the type of tumor. Compared with normal tissues, NFIC mRNA expression level was reduced in tumors in 18 studies involving 10 types of cancers, however, an increased level was observed in lymphomas and melanomas in only six studies. Regarding NFIX, 22 datasets revealed lower NFIX expression levels in 10 types of carcinomas with statistical significance, however, 10 analyses showed higher NFIX expression levels in brain and CNS cancer, esophageal cancer, melanoma, prostate cancer, 
121

122

123

124

125

126

127

128

129

130

131

132

133

134

135

136

137

and sarcoma. Taken together, most of the analyses showed the NFI transcriptional expression levels were significantly reduced in tumors compared with normal tissues.

\section{Transcription levels and prognostic significance of the NFI family members in breast cancer}

The mRNA expression levels of the NFI family members were first analyzed in breast cancer using the Oncomine database, which utilizes differential expression analyses by comparing most major types of cancer with respective normal tissues. In a total of 13 datasets, the differences in mRNA expression levels were compared between breast cancer and normal tissues. Analyses were available for NFIA, NFIB, and NFIX in all 13 datasets, and for NFIC in 12 datasets. The NFIA mRNA level was found significantly downregulated in numerous databases including Kamoub (Karnoub et al. 2007), Richardson2, (Richardson et al. 2006) Curtis (Curtis et al. 2012), TCGA, and Gluck (Gluck et al. 2012). However, the NFIA mRNA level was upregulated in invasive breast carcinoma in Finak's database (Finak et al. 2008). NFIB was significantly downregulated in 22 unique analyses across different breast cancer subtypes in 10 different databases including TCGA, Curtis (Curtis et al. 2012), Ma 4 (Ma et al. 2009), Zhao (Zhao et al. 2004),

Turashvili (Turashvili et al. 2007), Sorlie (Sorlie et al. 2001), Richardson2 (Richardson et al. 2006), Sorlie2 (Sorlie et al. 2003), Perou, and Gluck (Gluck et al. 2012; Perou et al. 2000). NFIC mRNA level was decreased in ductal breast carcinoma and lobular breast carcinoma in studies in which Richardson2 and Sorlie2 databases were utilized (Richardson et al. 2006; Sorlie et al. 2003). NFIX mRNA level was significantly reduced in multiple databases including Curtis (Curtis et al. 2012), Zhao (Zhao et al. 2004), Kamoub, and Gluck (Gluck et al. 2012; Karnoub et al. 2007) for invasive ductal breast carcinoma, invasive ductal and invasive lobular breast carcinoma, invasive ductal breast carcinoma, and invasive breast 
142

143

144

145

carcinoma, respectively. NFIX mRNA level was also significantly downregulated in ductal breast carcinoma compared with normal tissues in Sorlie (Sorlie et al. 2001), Perou, and Sorlie2 databases (Perou et al. 2000; Sorlie et al. 2003). The statistically significant results are summarized in Table 1. Next, the mRNA HiSeq expression data from TCGA database was utilized to further determine the expression of the NFI family members in breast cancer. As shown in Figure 2A, expression of all NFI family members was significantly downregulated in 1,104 cases of breast cancer compared with 114 normal samples. Next, the underlying mechanism of dysregulated expression of the NFI family was investigated using the cBioPortal online tool for breast invasive carcinoma (TCGA, Firehose Legacy). NFI genes were altered in 242 samples from 963 patients (25\%) with breast invasive carcinoma. Specifically, genetic alteration of the NFI genes was analyzed and depicted as oncoprints representing mutation, amplification, deep deletion, mRNA high, mRNA low, and multiple alterations (Fig. 2B-C). Survival analysis of the NFI genes with and without each gene alteration was conducted (Fig. S1). Breast invasive carcinoma patients with a NFIX gene alteration showed significantly poor overall survival (OS) and disease-free survival (DFS) compared with breast invasive carcinoma patients without NFIX gene alteration. In addition, the correlation between NFI gene expression and its DNA methylation was calculated using the cBioPortal online tool for breast invasive carcinoma (TCGA, Firehose Legacy), and Pearson's correction was included (Fig. 2D-G). The results indicated significant and negative correlations between NFI gene expression and corresponding DNA methylation in breast invasive carcinoma. Regression analysis confirmed a strongly negative correlation in NFIA (Pearson's $r=-0.64$ ) and NFIX (Pearson's $r=-0.76$ ), a moderately negative correlation in NFIB (Pearson's $r=-0.41$ ), and a weakly negative correlation in NFIC (Pearson's $r=-0.30$ ). 
Subsequently, the prognostic effects of the NFI family members were determined using the KM plotter database (www.kmplot.com) (Gyorffy et al. 2010). The breast oncology community currently describes breast cancer in terms of intrinsic biologic subtypes, and at least four subtypes are defined: basal-like (ER/PR-/HER2-), luminal A (ER+/HER2-/grade 1 or 2), luminal B (ER+/HER2-/grade 3), and HER2 enriched (any HER2+tumor). Therefore, prognosis analysis was investigated based on these four intrinsic subtypes.

The results showed decreased NFIA, NFIC, and NFIX expression predicted worse RFS in all patient subtypes. In addition, low NFIA expression was associated with poor recurrence-free survival (RFS), OS, and distant metastasis-free survival (DMFS) in luminal A subtype. Decreased NFIA expression showed better RFS, OS, and DMFS in the HER2-enriched subtype. Similarly, reduced NFIX expression indicated worse RFS in patients classified as luminal A but not in patients classified as HER2-enriched. In addition, downregulated NFIB expression was associated with better DMFS and post-progression survival (PPS) in basal-like patients. All the results are summarized in Table 2 and Table S1,(a-c) file.

\section{Transcription levels and prognostic significance of the NFI family members in lung cancer}

Similarly, the Oncomine database was utilized to compare the mRNA expression levels of the NFI family members in lung cancer and normal tissues. Using the same thresholds ( $p$-value $=0.01$; fold change $=2$; gene rank: 10\%, data type: mRNA), in Okayama and Hou's analysis, the NFIA mRNA expression level was significantly lower in lung adenocarcinoma (Hou et al. 2010; Okayama et al. 2012). According to Garber's database, NFIA expression was also downregulated in lung adenocarcinoma and large cell lung carcinoma (Garber et al. 2001). However, in SCLC and squamous cell lung carcinoma, opposite results were observed for NFIA in reporter IMAGE:364302 (high expression) and IMAGE:813154 (low expression). The NFIB 
183

184

mRNA expression level was significantly decreased in seven unique analyses, across different lung cancer subtypes, in five different databases including Stearman (Stearman et al. 2005), Bhattacharjee (Bhattacharjee et al. 2001), Garber (Garber et al. 2001), Wachi, and Hou (Hou et al. 2010; Wachi et al. 2005). Two comparisons with Bhattacharjee's database indicated the NFIC mRNA level was reduced in lung adenocarcinoma and SCLC (Bhattacharjee et al. 2001). NFIX expression was also lower in large cell lung carcinoma according to Garber's database (Garber et al. 2001). All statistically significant results are shown in Table 3. Next, the expression differences between lung cancer and normal tissues were evaluated using the mRNA HiSeq expression data from the TCGA database. There were 110 normal samples and 1,019 lung cancer samples, including 513 lung adenocarcinomas and 506 lung squamous cell carcinomas.

As shown in Figure 3A, the expression of the NFI family members in lung cancer tissues was significantly lower than in normal tissues. Next, the underlying mechanism of dysregulated expression of the NFI family was analyzed using the cBioPortal online tool for lung adenocarcinoma (TCGA, Firehose Legacy) and lung squamous cell carcinoma (TCGA, Firehose Legacy). NFI genes were altered in 58 samples of 230 patients (25\%) with lung adenocarcinoma and 41 samples of 178 patients $(23 \%)$ with lung squamous cell carcinoma.

The NFI genes in lung cancer were analyzed and depicted as oncoprints representing mutation, amplification, deep deletion, mRNA high, mRNA low, and multiple alterations (Fig. 3B-C and Fig. 3H-I). Survival analysis of the NFI genes with and without each gene alteration was conducted. Lung adenocarcinoma patients with NFIB gene alteration showed better DFS compared with lung adenocarcinoma patients without NFIB gene alteration (Fig. S2). Lung squamous cell carcinoma patients with NFIA gene alteration showed worse OS compared with lung squamous cell carcinoma patients without NFIA gene alterations (Fig. S3). In addition, the correlation between NFI gene expression and its DNA 
204

205

206

207

208

209

210

211

212

213

214

215

216

217

218

219

220

221

222

223

224

methylation was calculated using the cBioPortal online tool for lung adenocarcinoma (TCGA, Firehose

Legacy) and lung squamous cell carcinoma (TCGA, Firehose Legacy), and Pearson's correction was included. The results indicated significant and negative correlation between NFI gene expression and corresponding DNA methylation in lung adenocarcinoma (Fig. 3D-G) and lung squamous cell carcinoma (Fig. 3J-M). Regarding lung adenocarcinoma, regression analysis confirmed a strongly negative correlation in NFIX (Pearson's $r=-0.63$ ), a moderately negative correlation in NFIA (Pearson's $r=-0.47$ ) and NFIB (Pearson's $r=-0.45$ ), and a weakly negative correlation in NFIC (Pearson's $r=-0.21$ ). Regression analysis indicated a moderately negative correlation in NFIB (Pearson's $r=-0.53$ ) and NFIX (Pearson's $r=-0.42$ ) and a weakly negative correlation in NFIA (Pearson's $r=-0.38$ ). However, correlation between NFIC expression and methylation was not observed.

Next, the prognostic value of the NFI family members was assessed for lung cancer using the KM plotter database (Gyorffy et al. 2013). OS, first progression (FP), and PPS were analyzed for each gene. NFIC was uncorrelated with OS, FP, and PPS in patients with lung adenocarcinoma and squamous cell lung carcinoma. Decreased NFIA and NFIB expression predicted worse OS and FP in lung adenocarcinoma patients. Reduced NFIB expression was also associated with poor PPS. No gene showed statistical significance for squamous cell lung carcinoma patients except NFIX, which was associated with OS. All the detailed prognostic analyses are shown in Table 4 and in Table S2 (a,b) file.

\section{Transcription levels and prognostic significance of the NFI family members in bladder cancer}

For bladder cancer, all statistically significant datasets from the Oncomine database were extracted in Table

5. NFIA, NFIB, and NFIC expressions were decreased in both superficial bladder cancer and infiltrating 
225

226

227

228

229

230

231

232

233

234

235

236

237

238

239

240

241

242

243

244

245

bladder urothelial carcinoma compared with normal tissues in Lee (Lee et al. 2010) Sanchez-Carbayo2, and Blaveri2's studies (Blaveri et al. 2005; Sanchez-Carbayo et al. 2006). According to Lee's study, NFIX expression was reduced in superficial bladder cancer (Lee et al. 2010). Based on mRNA HiSeq expression data from the TCGA database, the expression of all NFI family members was significantly downregulated in 407 bladder cancer samples compared with 19 normal samples (Fig. 4A). Next, the cBioPortal online tool was used to investigate the underlying mechanism of dysregulated expression of the NFI family for bladder urothelial carcinoma (TCGA, Firehose Legacy). NFI genes were altered in 38 samples of 127 patients (30\%) with bladder urothelial carcinoma. Genetic alteration of the NFI genes was analyzed and depicted as oncoprints representing mutation, amplification, deep deletion, mRNA high, and multiple alterations (Fig. 4B-C). Survival analysis of the NFI genes with and without each gene alteration was conducted (Fig. S4). Bladder urothelial carcinoma patients with NFIB gene alteration showed significantly better OS compared with bladder urothelial patients without NFIB gene alteration. In addition, the correlation between NFI gene expression and its DNA methylation was calculated using the cBioPortal online tool for bladder urothelial carcinoma (TCGA, Firehose Legacy), and Pearson's correction was included (Fig. 4DG). The results indicated significantly negative correlation between NFI gene expression and corresponding DNA methylation in bladder urothelial carcinoma. Regression analysis confirmed a moderately negative correlation in NFIA (Pearson's $r=-0.42$ ) and a weakly negative correlation in NFIB (Pearson's $r=-0.37$ ) and NFIC (Pearson's $r=-0.31$ ). However, correlation between NFIX expression and its methylation was not observed (Pearson's $r=-0.16$ ).

Subsequently, the association between the NFI family members and the survival outcomes of bladder cancer patients using the KM plotter database was explored (Nagy et al. 2018). High expression of NFIA, 
246 NFIC, and NFIX predicted worse survival outcome in patients with bladder cancer. All the data are shown

247 in Table 6.

248

249

Transcription levels and prognostic significance of the NFI family members in head and neck cancer

For head and neck cancer, a total of six datasets from the Oncomine database were used to investigate

the mRNA expression of the NFI family members in tumors and normal tissues (Table 7). Ye's dataset

showed significantly decreased NFIA and NFIB mRNA expression level in tongue squamous cell carcinoma

(Ye et al. 2008). In addition, expression of NFIB and NFIX was downregulated in tongue squamous cell

carcinoma according to Estilo's study (Estilo et al. 2009). NFIA and NFIX were reduced in tonsillar

carcinoma, nasopharyngeal carcinoma, and oral cavity squamous cell carcinoma, respectively. In Cromer's

dataset, NFIB mRNA was significantly decreased in head and neck squamous cell carcinoma (Cromer et

al. 2004). Nevertheless, the NFIB mRNA expression level was significantly elevated in salivary gland

adenoid cystic carcinoma in FriersonHF's dataset (Frierson et al. 2002). Due to the limited number of cases

in the Oncomine database, 522 head and neck squamous cell carcinomas and 44 normal samples from

the TCGA database were further used to validate the potential expression differences of the NFI family 
267

268

269

270

271

272

273

274

275

276

277

278

279

280

281

282

283

284

285

286

287

amplification, deep deletion, mRNA high, and multiple alterations (Fig. 5B-C). Survival analysis of the NFI

genes with and without each gene alteration was conducted (Fig. S5). Head and neck cancer patients with

NFIA gene alteration showed better OS compared with head and neck cancer patients without NFIA gene

alteration. In addition, the correlation between NFI gene expression and its DNA methylation was calculated

using the cBioPortal online tool for head and neck squamous cell carcinoma (TCGA, Firehose Legacy), and

Pearson's correction was included (Fig. 5D-G). The results indicated significantly negative correlation

between NFI gene expression and corresponding DNA methylation in head and neck squamous cell

carcinoma. Regression analysis confirmed a moderately negative correlation in NFIB (Pearson's $r=-0.41$ )

and a weakly negative correlation in NFIA (Pearson's $r=-0.33$ ) and NFIX (Pearson's $r=-0.36$ ). Correlation

between NFIC expression and its methylation was not observed (Pearson's $r=-0.19$ ). However, only

survival data of head and neck squamous cell carcinoma from the KM plotter database were analyzed

(Nagy et al. 2018). The results showed all the NFI family members were associated with OS in head and

neck squamous cell carcinoma except NFIX. Higher expression levels of NFIA, NFIB, and NFIC implied better OS (Table 8).

\section{Transcription levels and prognostic significance of the NFI family members in esophageal cancer}

All statistically significant datasets for esophageal cancer were extracted in Table 9. NFIA was reduced in esophageal squamous cell carcinoma (ESCC), esophageal adenocarcinoma, and Barrett's esophagus in Su2 and Kim's datasets (Kim et al. 2010; Su et al. 2011). In Kim's study, the NFIB mRNA expression level was also downregulated in esophageal adenocarcinoma and Barrett's esophagus. However, Hao's dataset showed the opposite results for esophageal adenocarcinoma and Barrett's esophagus (Hao et al. 2006).

Peer) reviewing PDF | (2019:06:38719:2:0:NEW 18 Feb 2020) 
288

289

290

291

292

293

294

295

296

297

298

299

300

301

302

303

304

305

306

307

308

In the TCGA database, the expression of the NFI family members was decreased in esophageal cancer evaluated using the mRNA HiSeq expression data (Fig. 6A). Next, the underlying mechanism of dysregulated expression of the NFI family was investigated using the cBioPortal online tool for esophageal carcinoma (TCGA, Firehose Legacy). NFI genes were altered in 38 samples of 184 patients (21\%) with esophageal carcinoma. Genetic alteration of the NFI genes was analyzed and depicted as oncoprints representing mutation, amplification, deep deletion, mRNA high, and multiple alterations (Fig. 6B-C). Survival analysis of the NFI genes with and without each gene alteration was conducted (Fig. S6). However, significant difference in survival was not observed. In addition, the correlation between NFI gene expression and its DNA methylation was calculated using the cBioPortal online tool for esophageal carcinoma (TCGA, Firehose Legacy), and Pearson's correction was included (Fig. 6D-G). The results indicated significantly negative correlation between NFI gene expression and corresponding DNA methylation in esophageal carcinoma. Regression analysis confirmed a moderately negative correlation in NFIB (Pearson's $r=-0.4$ ) and NFIX (Pearson's $r=-0.51$ ), a weakly negative correlation in NFIA (Pearson's $r=-0.32$ ) and NFIC (Pearson's $r=-0.33$ ). The correlation between expression of the NFI family members and survival outcome involving OS in esophageal cancer patients was then determined using the KM plotter database. Low expression of NFIC and NFIX revealed poor prognosis in esophageal adenocarcinoma patients. The details are shown in Table $10(a, b)$.

\section{Transcription levels and prognostic significance of the NFI family members in kidney cancer}

For kidney cancer, Higgins's dataset showed the NFIA mRNA expression level was upregulated in clear cell sarcoma of the kidney compared with normal kidney tissues (Higgins et al. 2003). NFIB was 
309

310

311

312

313

314

315

316

317

318

319

320

321

322

323

324

325

326

327

328

329

overexpressed in clear cell sarcoma of the kidney and papillary renal cell carcinoma according to Cutcliffe

and Jones's datasets (Cutcliffe et al. 2005; Jones et al. 2005). However, in Cutcliffe's dataset, NFIB

expression was reduced in Wilms tumor. In addition, two analyses with Yusenko's dataset showed lower

NFIB mRNA levels in chromophobe renal cell carcinoma and renal oncocytoma (Yusenko et al. 2009). All

statistically significant results are summarized in Table 11. Furthermore, analyses were performed for

kidney chromophobe cell carcinoma (Fig. 7A), kidney clear cell carcinoma (Fig. 8A), and kidney papillary

cell carcinoma (Fig. 9A) using the mRNA HiSeq expression data from the TCGA database. Consistent with

the trend observed in the Oncomine database, NFIA, NFIB, and NFIX were significantly overexpressed in

kidney clear cell carcinoma compared with normal kidney tissue. In addition, expression of NFIA and NFIB

was downregulated in kidney chromophobe cell carcinoma, whereas expression of NFIC and NFIX was

upregulated. Contrary to kidney chromophobe cell carcinoma, expression of NFIA and NFIB was

upregulated in kidney papillary cell carcinoma and expression of NFIC and NFIX was reduced.

Subsequently, the underlying mechanism of dysregulated expression of the NFI family was investigated

using the cBioPortal online tool for kidney chromophobe cell carcinoma (TCGA, Firehose Legacy), kidney

renal clear cell carcinoma (TCGA, Firehose Legacy) and kidney renal papillary cell carcinoma (TCGA,

Firehose Legacy). NFI genes were altered in 11 samples of 66 patients (11\%) with kidney chromophobe

cell carcinoma, 72 samples of 448 patients (16\%) with kidney renal clear cell carcinoma, and 55 samples

of 280 patients $(20 \%)$ with kidney renal papillary cell carcinoma. The NFI genes in kidney cancer were

analyzed and depicted as oncoprints representing mutation, amplification, deep deletion, mRNA high,

mRNA low, and multiple alterations (Fig. 7B-C, 8B-C, and 9B-C). Survival analysis of the NFI genes with

and without each gene alteration was conducted. Kidney renal clear cell carcinoma patients with NFIA gene

Peer] reviewing PDF | (2019:06:38719:2:0:NEW 18 Feb 2020) 
330

331

332

333

334

335

336

337

338

339

340

341

342

343

344

345

346

347

348

349

350

alteration showed significantly poor OS and DFS compared with kidney renal clear cell carcinoma patients

without NFIA gene alteration (Fig. S8). Kidney renal papillary cell carcinoma patients with NFIX gene

alteration showed worse OS compared with kidney renal papillary cell carcinoma patients without NFIX gene alteration (Fig. S9). However, significant difference in survival for kidney chromophobe cell carcinoma patients was not observed (Fig. S7). In addition, the correlation between NFI gene expression and its DNA methylation was calculated using the cBioPortal online tool for kidney chromophobe cell carcinoma (TCGA, Firehose Legacy), kidney renal clear cell carcinoma (TCGA, Firehose Legacy), and kidney renal papillary cell carcinoma (TCGA, Firehose Legacy), and Pearson's correction was included. The results indicated significantly negative correlation between NFI gene expression and corresponding DNA methylation in kidney cancer. Regarding kidney chromophobe cell carcinoma (Fig. 7D-G), regression analysis confirmed a moderately negative correlation in NFIA (Pearson's $r=-0.4$ ), NFIC (Pearson's $r=-0.4$ ) and NFIX (Pearson's $r=-0.42$ ). Correlation between NFIB expression and its DNA methylation was not observed (Pearson's $r=-0.11)$. In kidney renal clear cell carcinoma (Fig. 8D-G), regression analysis indicated a strongly negative correlation in NFIA (Pearson's $r=-0.61$ ), a moderately negative correlation in NFIX (Pearson's $r=-0.44$ ), and a weakly negative correlation in NFIB (Pearson's $r=-0.39$ ). Correlation between NFIC expression and its methylation was not observed (Pearson's $r=-0.19$ ). In addition, regression analysis confirmed a moderately negative correlation in NFIA (Pearson's $r=-0.52$ ) and NFIB (Pearson's $r$ $=-0.47$ ), a weakly negative correlation in NFIX (Pearson's $r=-0.36$ ), and no correlation in NFIC (Pearson's $r=-0.18$ ) for kidney renal papillary cell carcinoma (Fig. 9D-G). Next, the prognostic significance associated with the expression of the NFI family members was evaluated using the KM plotter database (Nagy et al. 2018). The results showed low expression of the NFI family members predicted worse OS in kidney clear 
351

352

353

354

355

356

357

358

359

360

361

362

363

364

cell carcinoma. Reduced expression of NFIA and NFIX was significantly associated with better RFS. In kidney papillary cell carcinoma, decreased NFIB mRNA level was significantly correlated with worse OS and RFS. Decreased NFIA expression was also associated with worse OS but not RFS. Conversely, low

NFIX expression predicted better OS. The details are shown in Table $12(a, b)$. However, the survival data for kidney chromophobe cell carcinoma were not available in the KM plotter or SurvExpress database.

\section{Transcription levels and prognostic significance of the NFI family members in other cancers}

The Oncomine database showed significant differences in mRNA expression of NFIB and NFIC between cervical cancer and normal tissues (Fig. 1). The details are shown in Table S3. NFIB expression was downregulated in high grade cervical squamous and cervical squamous cell carcinoma analyzed according to Zhai and Scotto's datasets, respectively (Scotto et al. 2008; Zhai et al. 2007). In Biewenga's study (Biewenga et al. 2008), the NFIC mRNA expression was also reduced in cervical squamous cell carcinoma compared with normal tissues. However, the difference in expression of the NFI family members between tumors and normal tissues in the TCGA database could not be compared due to the lack of normal samples. Subsequently, the prognostic value associated with the expression of the NFI family members was determined using the KM plotter database. The results showed lower mRNA expression of NFIB, NFIC, and NFIX predicted worse OS in cervical squamous cell carcinoma. In addition, elevated NFIA and NFIB mRNA levels were significantly associated with worse RFS (Table S4 File).

For colorectal cancer, analysis using the Oncomine database revealed significant difference only in NFIA and NFIB mRNA levels between tumor and normal samples (Table S5). Expression of NFIA and NFIB was downregulated in colorectal cancer according to the TCGA database. However, NFIA expression was 
372 increased in rectal mucinous adenocarcinoma and cecum adenocarcinoma in Kaiser's study (Kaiser et al.

373 2007). NFIB mRNA level was upregulated in colon adenoma according to Skrzypczak's dataset

374 (Skrzypczak et al. 2010). Expression of NFIA, NFIB, and NIFC was reduced in colorectal cancer tissues

375 evaluated based on mRNA HiSeq expression data from the TCGA database (Fig. S10). Next, the prognostic

376 significance associated with the expression of the NFI family members was evaluated using the KM plotter

377 database. Only NFIX expression was associated with OS in colorectal cancer patients (Table S6).

378 For gastric cancer, NFIB and NFIX mRNA levels were not significantly different between tumor and normal

379 tissues (Table S7). DErrico's dataset showed overexpression of the NFIB gene. However, NFIX mRNA

380 level was significantly downregulated in gastric mixed adenocarcinoma (D'Errico et al. 2009). Due to the

381 limited number of cases in the Oncomine database, 380 gastric cancers and 37 normal samples from the

382 TCGA database were further used to confirm the potential expression differences of the NFI family

383 members between tumors and normal tissues. NFIB expression was elevated in gastric cancer. However,

384 the NFIC mRNA level was downregulated in gastric cancer compared with normal tissues (Fig. S11).

385 Subsequently, to ascertain the prognostic value associated with the expression of the NFI family members

386 in gastric cancer, OS, PPS, and FP were evaluated using the KM plotter database. The prognostic effects

387 of the four genes are shown in Table S8. Low expression of NFIC and NFIX predicted poor OS in gastric

388 cancer patients. In addition, reduced NFIX expression was significantly associated with worse FP in gastric

389 cancer patients. Next, the prognostic ability of NFI expression was investigated in different HER2 statuses

390 of gastric cancer. As shown in Table S8 $(\mathrm{a}-\mathrm{c})$, only reduced NFIX mRNA expression could predict worse

391 OS, FP, and PPS in the HER2-positive group. However, in the HER2-negative group, NFIB and NFIC 
392

393

394

395

396

397

398

399

400

401

402

403

404

405

406

407

408

409

410

411

412

expression was significantly correlated with better OS and decreased NFIX expression was associated with better PPS.

For liver cancer, analysis using the Oncomine database revealed only NFIA mRNA level was significantly downregulated in tumor tissues according to Wurmbach's dataset (Wurmbach et al. 2007). Other genes of the NFI family did not show any significant difference between tumors and normal tissues (Table S9). NFIA, NFIB, and NFIC expression levels were reduced in cancer tissues evaluated using mRNA HiSeq expression data from the TCGA database (Fig. S3). In the KM plotter database, high NFIA and NFIX expression predicted better OS and disease-specific survival (DSS) in liver cancer patients. Besides, decreased NFIC expression level was associated with poor PFS and NFIB expression was uncorrelated with OS in liver cancer patients (Table S10).

For prostate cancer, the Oncomine database was used to compare the mRNA expression levels of the NFI family members between cancer and normal tissues. The results showed NFIB expression was upregulated in prostate adenocarcinoma according to Wallace's dataset (Wallace et al. 2008), however, the opposite results were found in Tomlins's study (Tomlins et al. 2007). NFIC mRNA levels were downregulated in prostate carcinoma according to Luo2's dataset (Luo et al. 2002). NFIX expression was lower in prostate carcinoma in Varambally's study (Varambally et al. 2005), but higher in benign prostate hyperplasia according to Tomlins's dataset (Tomlins et al. 2007). The details are shown in Table S11. In the TCGA database, NFIA, NFIB, and NFIC mRNA levels were significantly downregulated in prostate cancer patients. However, a significant upregulation of NFIX mRNA levels was observed in tumor tissues (Fig. S13). Alternatively, the prognostic significance associated with the expression of the NFI family members was determined using the SurvExpress database because survival data for prostate cancer was absent in the 
$413 \mathrm{KM}$ plotter database. The results showed no significant association between expression of the NFI family

414 members and survival outcome in prostate cancer patients (Fig. S14).

\section{Discussion}

416 The NFI transcription factors play an important role in normal development and are related to human

417 dysplasia. Due to the advancement of high-throughput sequencing technology, the NFI family has been

418 found to play an important role in the development of various tumors. In this study, the mRNA expression

419 levels of the NFI family members were comprehensively analyzed in various types of cancers using the

420 Oncomine and TCGA databases. The results showed the mRNA expression levels of the NFI family were

421 significantly downregulated in breast, bladder, lung, esophageal, and head and neck cancers compared

422 with normal tissues. In addition, the transcriptional pattern of the NFI family was different among the three

423 subtypes of kidney cancer. For example, the expression of NFIA and NFIB was reduced in kidney

424 chromophobe cell carcinoma but not in papillary or clear cell carcinoma; however, mRNA expression levels

425 were elevated. Furthermore, NFIB expression was increased in gastric cancer. Then, the cBioPortal online

426 tool was used to investigate the underlying mechanism of dysregulated expression of the NFI family in

427 breast, bladder, lung, esophageal, kidney, and head and neck cancers. Genomic analysis showed the

428 mRNA high percentage of NFIA, NFIB, NFIC, and NFIX was higher than in other gene alterations, including

429 gene mutation, amplification, and deep deletion. Survival analysis indicated that almost none of the NFI

430 genes with gene alterations were associated with OS or DFS. These findings indicate that NFI gene

431 alterations might not independently influence its transcription in various tumors. In addition, by comparing

432 the mRNA expression level of each NFI family member with its corresponding DNA methylation, a certain 
433

434

435

436

437

438

439

440

441

442 443 (Ge et al. 2018).

444

445

446

447

448

449

450

451

452

453

negative correlation was observed, indicating that methylation may be one reason for the decreased expression levels of the NFI family.

Reportedly, the NFI transcription factors are significantly associated with various clinicopathological features and survival outcomes in cancer patients. In bladder cancer, elevated NFIA mRNA expression was associated with T1 progressive bladder cancer compared with T1 nonprogressive tumors (Sharron Lin et al. 2014). Stringer et al. demonstrated that low NFIB mRNA expression was associated with increased astrocytoma grade and mesenchymal subtype of glioblastoma. Glioblastoma multiforme (GBM) patients with higher NFIB expression survived significantly longer than patients with lower NFIB expression (Stringer et al. 2016). In another study, NFIX DNA hypermethylation was reportedly associated with significantly decreased NFIX expression and was related to shorter OS and RFS in patients with lung adenocarcinoma

However, only a limited number of studies have investigated the prognostic significance of the NFI transcription factors in human cancers. In a previous study, high NFIA expression was shown an independent predictor of poor prognosis in esophageal squamous carcinoma, and high NFIB expression was a negative prognostic value in esophagogastric junction adenocarcinoma (Yang et al. 2018). Therefore, the mRNA expression of certain NFI transcription factors might correlate with survival outcomes in cancer patients. In the present study, high expression of NFIA, NFIB, and NFIX was significantly associated with improved prognosis in breast cancer. In addition, these significant correlations were present specifically in the luminal A and HER2+ subtypes of breast cancer. Decreased NFIA mRNA expression indicated better OS, RFS, and DMFS in breast cancer patients with HER2+ subtype but worse OS, RFS, and DMFS in luminal A subtype patients. In lung cancer, expression of NFIA and NFIB was correlated with better 
454 prognosis. However, such correlations might only be applicable to lung adenocarcinomas but not squamous

455 cell carcinoma. All four genes were significantly associated with poor prognosis in ovarian cancer. In gastric

456 cancer, high NFIX expression was significantly correlated with better overall prognosis in gastric cancer

457 and HER2+ gastric cancer, and marginally correlated with PPS in HER2- gastric cancer. Reduced mRNA

458 expression of NFIA, NFIB, and NFIX predicted better OS in bladder cancer. Furthermore, statistical

459 correlations were found between mRNA expression of the different NFI family members and survival

460 outcomes in head and neck, liver, kidney, cervical, esophageal, and pancreatic cancers, as well as

461 sarcoma. Taken together, the data indicate the NFI family members may be used as prognostic biomarkers

462 in many cancers.

463 Recently, accumulating evidence indicated the NFI transcription factors have both oncogenic and tumor-

464 suppressive potential, depending on the context. For example, NFIB, the most well studied NFI transcription

465 factor, might be oncogenic in SCLC (Dooley et al. 2011), melanoma, and breast cancer (Fane et al. 2017;

466 Liu et al. 2019), but likely functions as a tumor suppressor in NSCLC (Becker-Santos et al. 2016),

467 osteosarcoma (Mirabello et al. 2015), glioma, and glioblastoma (Stringer et al. 2016; Suzuki et al. 2015).

468 Similarly, NFIB and NFIC could function in an opposing role. The breast cancer cell line, MCF7, treated

469 with NFIC siRNA, enhanced EMT, motility, migration, and invasion (Lee et al. 2015). Conversely, depletion

470 of NFIB in p53-mutated triple-negative breast cancer cell lines MDA-MB-435, HCC1806, and BT-20,

471 promoted cell death, cell cycle arrest, and enhanced sensitivity to docetaxel, a first-line chemotherapeutic

472 drug used in breast cancer treatment (Liu et al. 2019). Furthermore, NFIA inhibited cell death and enhanced

473 cell survival, proliferation, and migration in GBM by negatively regulating p53, p21, and PAl1 (Kang et al.

474 2016). In ESCC cells, NFIX overexpression inhibited cell proliferation, migration, and invasion (Mao et al. 
475 2015). In the present study, based on the large databases in Oncomine and TCGA, the mRNA expression

476 levels of the NFI family members were downregulated in various types of cancer. Genomic analysis showed

477 the alterations in each NFI family gene were less frequent in various tumors and had little influence on

478 survival outcomes. In addition, the correlation between NFI gene expression and its DNA methylation was

479 calculated using the cBioPortal online tool for breast, bladder, lung, esophageal, kidney, and head and neck

480 cancers. A certain negative correlation was observed, indicating that epigenetic alteration is an important

481 mechanism of dysregulated NFI expression in human cancers. When generating Kaplan-Meier curves,

482 statistical correlations were found between mRNA expression of the NFI family genes and survival

483 outcomes in multiple tumors. Therefore, we hypothesized the NFI family might play an important role in

484 tumor processes, and further investigation of the underlying molecular mechanisms in multiple cancers is

485 necessary.

\section{Conclusion}

487 In the present study, the mRNA expression levels, genetic alteration, DNA methylation, and prognostic significance of the NFI family were systematically analyzed in different human cancers using the Oncomine,

TCGA, KM plotter, SurvExpress databases, and cBioPortal for Cancer Genomics. Based on the large

492 Furthermore, several of the NFI genes showed great prognostic significance for cancer patients. Therefore, 
494 495

496

497

498

499

500

501

502

503

504

505

506

507

508

509

510

511

512

513

514

515

516

517

518

519

520

521

522

523

development, which may confirm the NFI family members are promising therapeutic targets and novel

prognostic biomarkers for human cancers.

\section{Acknowledgments}

This work was supported by the National Natural Science Foundation of China (81472806)

\section{Disclosure}

The author reports no conflicts of interest in this work.

\section{References}

Aguirre-Gamboa R, Gomez-Rueda H, Martinez-Ledesma E, Martinez-Torteya A, Chacolla-Huaringa R, Rodriguez-Barrientos A, Tamez-Pena JG, and Trevino V. 2013. SurvExpress: an online biomarker validation tool and database for cancer gene expression data using survival analysis. PLoS One 8:e74250. 10.1371/journal.pone.0074250

Becker-Santos DD, Thu KL, English JC, Pikor LA, Martinez VD, Zhang M, Vucic EA, Luk MT, Carraro A, Korbelik J, Piga D, Lhomme NM, Tsay MJ, Yee J, MacAulay CE, Lam S, Lockwood WW, Robinson WP, Jurisica I, and Lam WL. 2016. Developmental transcription factor NFIB is a putative target of oncofetal miRNAs and is associated with tumour aggressiveness in lung adenocarcinoma. J Pathol 240:161-172. 10.1002/path.4765

Bhattacharjee A, Richards WG, Staunton J, Li C, Monti S, Vasa P, Ladd C, Beheshti J, Bueno R, Gillette M, Loda M, Weber G, Mark EJ, Lander ES, Wong W, Johnson BE, Golub TR, Sugarbaker DJ, and Meyerson M. 2001. Classification of human lung carcinomas by mRNA expression profiling reveals distinct adenocarcinoma subclasses. Proc Natl Acad Sci U S A 98:13790-13795. 10.1073/pnas.191502998

Biewenga P, Buist MR, Moerland PD, Ver Loren van Themaat E, van Kampen AH, ten Kate FJ, and Baas F. 2008. Gene expression in early stage cervical cancer. Gynecol Oncol 108:520-526. 10.1016/j.ygyno.2007.11.024

Blaveri E, Simko JP, Korkola JE, Brewer JL, Baehner F, Mehta K, Devries S, Koppie T, Pejavar S, Carroll $\mathrm{P}$, and Waldman FM. 2005. Bladder cancer outcome and subtype classification by gene expression. Clin Cancer Res 11:4044-4055. 10.1158/1078-0432.CCR-04-2409

Bray F, Ferlay J, Soerjomataram I, Siegel RL, Torre LA, and Jemal A. 2018. Global cancer statistics 2018: GLOBOCAN estimates of incidence and mortality worldwide for 36 cancers in 185 countries. CA Cancer J Clin 68:394-424. 10.3322/caac.21492 
524

525

526

527

528

529

530

531

532

533

534

535

536

537

538

539

540

541

542

543

544

545

546

547

548

549

550

551

552

553

554

555

556

557

558

559

560

561

562

Cerami E, Gao J, Dogrusoz U, Gross BE, Sumer SO, Aksoy BA, Jacobsen A, Byrne CJ, Heuer ML, Larsson E, Antipin Y, Reva B, Goldberg AP, Sander C, and Schultz N. 2012. The cBio cancer genomics portal: an open platform for exploring multidimensional cancer genomics data. Cancer Discov 2:401-404. 10.1158/2159-8290.CD-12-0095

Cromer A, Carles A, Millon R, Ganguli G, Chalmel F, Lemaire F, Young J, Dembele D, Thibault C, Muller D, Poch O, Abecassis J, and Wasylyk B. 2004. Identification of genes associated with tumorigenesis and metastatic potential of hypopharyngeal cancer by microarray analysis. Oncogene 23:2484-2498. 10.1038/sj.onc.1207345

Curtis C, Shah SP, Chin SF, Turashvili G, Rueda OM, Dunning MJ, Speed D, Lynch AG, Samarajiwa S, Yuan Y, Graf S, Ha G, Haffari G, Bashashati A, Russell R, McKinney S, Group M, Langerod A, Green A, Provenzano E, Wishart G, Pinder S, Watson P, Markowetz F, Murphy L, Ellis I, Purushotham A, Borresen-Dale AL, Brenton JD, Tavare S, Caldas C, and Aparicio S. 2012. The genomic and transcriptomic architecture of 2,000 breast tumours reveals novel subgroups. Nature 486:346-352. 10.1038/nature10983

Cutcliffe C, Kersey D, Huang CC, Zeng Y, Walterhouse D, Perlman EJ, and Renal Tumor Committee of the Children's Oncology G. 2005. Clear cell sarcoma of the kidney: up-regulation of neural markers with activation of the sonic hedgehog and Akt pathways. Clin Cancer Res 11:7986-7994. 10.1158/1078-0432.CCR-05-1354

D'Errico M, de Rinaldis E, Blasi MF, Viti V, Falchetti M, Calcagnile A, Sera F, Saieva C, Ottini L, Palli D, Palombo F, Giuliani A, and Dogliotti E. 2009. Genome-wide expression profile of sporadic gastric cancers with microsatellite instability. Eur J Cancer 45:461-469. 10.1016/j.ejca.2008.10.032

Dooley AL, Winslow MM, Chiang DY, Banerji S, Stransky N, Dayton TL, Snyder EL, Senna S, Whittaker CA, Bronson RT, Crowley D, Barretina J, Garraway L, Meyerson M, and Jacks T. 2011. Nuclear factor I/B is an oncogene in small cell lung cancer. Genes Dev 25:1470-1475. 10.1101/gad.2046711

Estilo CL, P Oc, Talbot S, Socci ND, Carlson DL, Ghossein R, Williams T, Yonekawa Y, Ramanathan Y, Boyle JO, Kraus DH, Patel S, Shaha AR, Wong RJ, Huryn JM, Shah JP, and Singh B. 2009. Oral tongue cancer gene expression profiling: Identification of novel potential prognosticators by oligonucleotide microarray analysis. BMC Cancer 9:11. 10.1186/1471-2407-9-11

Fane ME, Chhabra Y, Hollingsworth DEJ, Simmons JL, Spoerri L, Oh TG, Chauhan J, Chin T, Harris L, Harvey TJ, Muscat GEO, Goding CR, Sturm RA, Haass NK, Boyle GM, Piper M, and Smith AG. 2017. NFIB Mediates BRN2 Driven Melanoma Cell Migration and Invasion Through Regulation of EZH2 and MITF. EBioMedicine 16:63-75. 10.1016/j.ebiom.2017.01.013

Finak G, Bertos N, Pepin F, Sadekova S, Souleimanova M, Zhao H, Chen H, Omeroglu G, Meterissian S, Omeroglu A, Hallett M, and Park M. 2008. Stromal gene expression predicts clinical outcome in breast cancer. Nat Med 14:518-527. 10.1038/nm1764

Frierson HF, Jr., El-Naggar AK, Welsh JB, Sapinoso LM, Su Al, Cheng J, Saku T, Moskaluk CA, and Hampton GM. 2002. Large scale molecular analysis identifies genes with altered expression in salivary adenoid cystic carcinoma. Am J Pathol 161:1315-1323. 10.1016/S0002-9440(10)64408-2

Peer) reviewing PDF | (2019:06:38719:2:0:NEW 18 Feb 2020) 
563

564

565

566

567

568

569

570

571

572

573

574

575

576

577

578

579

580

581

582

583

584

585

586

587

588

589

590

591

592

593

594

595

596

597

598

599

600

601

602

603

Gao J, Aksoy BA, Dogrusoz U, Dresdner G, Gross B, Sumer SO, Sun Y, Jacobsen A, Sinha R, Larsson E, Cerami E, Sander C, and Schultz N. 2013. Integrative analysis of complex cancer genomics and clinical profiles using the cBioPortal. Sci Signal 6:pl1. 10.1126/scisignal.2004088

Garber ME, Troyanskaya OG, Schluens K, Petersen S, Thaesler Z, Pacyna-Gengelbach M, van de Rijn M, Rosen GD, Perou CM, Whyte RI, Altman RB, Brown PO, Botstein D, and Petersen I. 2001. Diversity of gene expression in adenocarcinoma of the lung. Proc Natl Acad Sci U S A 98:1378413789. 10.1073/pnas.241500798

Ge J, Dong H, Yang Y, Liu B, Zheng M, Cheng Q, Peng L, and Li J. 2018. NFIX downregulation independently predicts poor prognosis in lung adenocarcinoma, but not in squamous cell carcinoma. Future Oncol 14:3135-3144. 10.2217/fon-2018-0164

Gluck S, Ross JS, Royce M, McKenna EF, Jr., Perou CM, Avisar E, and Wu L. 2012. TP53 genomics predict higher clinical and pathologic tumor response in operable early-stage breast cancer treated with docetaxel-capecitabine +/- trastuzumab. Breast Cancer Res Treat 132:781-791. 10.1007/s10549-011-1412-7

Gyorffy B, Lanczky A, Eklund AC, Denkert C, Budczies J, Li Q, and Szallasi Z. 2010. An online survival analysis tool to rapidly assess the effect of 22,277 genes on breast cancer prognosis using microarray data of 1,809 patients. Breast Cancer Res Treat 123:725-731. 10.1007/s10549-0090674-9

Gyorffy B, Surowiak P, Budczies J, and Lanczky A. 2013. Online survival analysis software to assess the prognostic value of biomarkers using transcriptomic data in non-small-cell lung cancer. PLoS One 8:e82241. 10.1371/journal.pone.0082241

Hao Y, Triadafilopoulos G, Sahbaie P, Young HS, Omary MB, and Lowe AW. 2006. Gene expression profiling reveals stromal genes expressed in common between Barrett's esophagus and adenocarcinoma. Gastroenterology 131:925-933. 10.1053/j.gastro.2006.04.026

Higgins JP, Shinghal R, Gill H, Reese JH, Terris M, Cohen RJ, Fero M, Pollack JR, van de Rijn M, and Brooks JD. 2003. Gene expression patterns in renal cell carcinoma assessed by complementary DNA microarray. Am J Pathol 162:925-932. 10.1016/S0002-9440(10)63887-4

Hou J, Aerts J, den Hamer B, van ljcken W, den Bakker M, Riegman P, van der Leest C, van der Spek P, Foekens JA, Hoogsteden HC, Grosveld F, and Philipsen S. 2010. Gene expression-based classification of non-small cell lung carcinomas and survival prediction. PLoS One 5:e10312. 10.1371/journal.pone.0010312

Jones J, Otu H, Spentzos D, Kolia S, Inan M, Beecken WD, Fellbaum C, Gu X, Joseph M, Pantuck AJ, Jonas D, and Libermann TA. 2005. Gene signatures of progression and metastasis in renal cell cancer. Clin Cancer Res 11:5730-5739. 10.1158/1078-0432.CCR-04-2225

Kaiser S, Park YK, Franklin JL, Halberg RB, Yu M, Jessen WJ, Freudenberg J, Chen X, Haigis K, Jegga AG, Kong S, Sakthivel B, Xu H, Reichling T, Azhar M, Boivin GP, Roberts RB, Bissahoyo AC, Gonzales F, Bloom GC, Eschrich S, Carter SL, Aronow JE, Kleimeyer J, Kleimeyer M, Ramaswamy V, Settle SH, Boone B, Levy S, Graff JM, Doetschman T, Groden J, Dove WF, Threadgill DW, Yeatman TJ, Coffey RJ, Jr., and Aronow BJ. 2007. Transcriptional recapitulation and subversion of embryonic colon development by mouse colon tumor models and human colon cancer. Genome Biol 8:R131. 10.1186/gb-2007-8-7-r131

Peer] reviewing PDF | (2019:06:38719:2:0:NEW 18 Feb 2020) 
604

605

606

607

608

609

610

611

612

613

614

615

616

617

618

619

620

621

622

623

624

625

626

627

628

629

630

631

632

633

634

635

636

637

638

639

640

641

642

Kang CM, Hu YW, Nie Y, Zhao JY, Li SF, Chu S, Li HX, Huang QS, and Qiu YR. 2016. Long non-coding RNA RP5-833A20.1 inhibits proliferation, metastasis and cell cycle progression by suppressing the expression of NFIA in U251 cells. Mol Med Rep 14:5288-5296. 10.3892/mmr.2016.5854

Karnoub AE, Dash AB, Vo AP, Sullivan A, Brooks MW, Bell GW, Richardson AL, Polyak K, Tubo R, and Weinberg RA. 2007. Mesenchymal stem cells within tumour stroma promote breast cancer metastasis. Nature 449:557-563. 10.1038/nature06188

Kim SM, Park YY, Park ES, Cho JY, Izzo JG, Zhang D, Kim SB, Lee JH, Bhutani MS, Swisher SG, Wu X, Coombes KR, Maru D, Wang KK, Buttar NS, Ajani JA, and Lee JS. 2010. Prognostic biomarkers for esophageal adenocarcinoma identified by analysis of tumor transcriptome. PLoS One 5:e15074. 10.1371/journal.pone.0015074

Kruse U, and Sippel AE. 1994. Transcription factor nuclear factor I proteins form stable homo- and heterodimers. FEBS Lett 348:46-50.

Lee HK, Lee DS, and Park JC. 2015. Nuclear factor I-C regulates E-cadherin via control of KLF4 in breast cancer. BMC Cancer 15:113. 10.1186/s12885-015-1118-z

Lee JS, Leem SH, Lee SY, Kim SC, Park ES, Kim SB, Kim SK, Kim YJ, Kim WJ, and Chu IS. 2010. Expression signature of E2F1 and its associated genes predict superficial to invasive progression of bladder tumors. J Clin Oncol 28:2660-2667. 10.1200/JCO.2009.25.0977

Leegwater PA, van Driel W, and van der Vliet PC. 1985. Recognition site of nuclear factor I, a sequencespecific DNA-binding protein from HeLa cells that stimulates adenovirus DNA replication. EMBO $J$ 4:1515-1521.

Liu RZ, Vo TM, Jain S, Choi WS, Garcia E, Monckton EA, Mackey JR, and Godbout R. 2019. NFIB promotes cell survival by directly suppressing p21 transcription in TP53-mutated triple-negative breast cancer. J Pathol 247:186-198. 10.1002/path.5182

Luo JH, Yu YP, Cieply K, Lin F, Deflavia P, Dhir R, Finkelstein S, Michalopoulos G, and Becich M. 2002. Gene expression analysis of prostate cancers. Mol Carcinog 33:25-35.

Ma XJ, Dahiya S, Richardson E, Erlander M, and Sgroi DC. 2009. Gene expression profiling of the tumor microenvironment during breast cancer progression. Breast Cancer Res 11:R7. 10.1186/bcr2222

Mao Y, Liu J, Zhang D, and Li B. 2015. MiR-1290 promotes cancer progression by targeting nuclear factor I/X(NFIX) in esophageal squamous cell carcinoma (ESCC). Biomed Pharmacother 76:8293. 10.1016/j.biopha.2015.10.005

Mirabello L, Koster R, Moriarity BS, Spector LG, Meltzer PS, Gary J, Machiela MJ, Pankratz N, Panagiotou OA, Largaespada D, Wang Z, Gastier-Foster JM, Gorlick R, Khanna C, de Toledo SR, Petrilli AS, Patino-Garcia A, Sierrasesumaga L, Lecanda F, Andrulis IL, Wunder JS, Gokgoz N, Serra M, Hattinger C, Picci P, Scotlandi K, Flanagan AM, Tirabosco R, Amary MF, Halai D, Ballinger ML, Thomas DM, Davis S, Barkauskas DA, Marina N, Helman L, Otto GM, Becklin KL, Wolf NK, Weg MT, Tucker M, Wacholder S, Fraumeni JF, Jr., Caporaso NE, Boland JF, Hicks BD, Vogt A, Burdett L, Yeager M, Hoover RN, Chanock SJ, and Savage SA. 2015. A GenomeWide Scan Identifies Variants in NFIB Associated with Metastasis in Patients with Osteosarcoma. Cancer Discov 5:920-931. 10.1158/2159-8290.CD-15-0125

Peer] reviewing PDF | (2019:06:38719:2:0:NEW 18 Feb 2020) 
643 Nagata K, Guggenheimer RA, Enomoto T, Lichy JH, and Hurwitz J. 1982. Adenovirus DNA replication in

644

645

646

647

648

649

650

651

652

653

654

655

656

657

658

659

660

661

662

663

664

665

666

667

668

669

670

671

672

673

674

675

676

677

678

679

680

681

682

683 vitro: identification of a host factor that stimulates synthesis of the preterminal protein-dCMP complex. Proc Natl Acad Sci U S A 79:6438-6442. 10.1073/pnas.79.21.6438

Nagy A, Lanczky A, Menyhart O, and Gyorffy B. 2018. Validation of miRNA prognostic power in hepatocellular carcinoma using expression data of independent datasets. Sci Rep 8:9227. 10.1038/s41598-018-27521-y

Okayama H, Kohno T, Ishii Y, Shimada Y, Shiraishi K, Iwakawa R, Furuta K, Tsuta K, Shibata T, Yamamoto S, Watanabe S, Sakamoto H, Kumamoto K, Takenoshita S, Gotoh N, Mizuno H, Sarai A, Kawano S, Yamaguchi R, Miyano S, and Yokota J. 2012. Identification of genes upregulated in ALK-positive and EGFR/KRAS/ALK-negative lung adenocarcinomas. Cancer Res 72:100-111. 10.1158/0008-5472.CAN-11-1403

Perou CM, Sorlie T, Eisen MB, van de Rijn M, Jeffrey SS, Rees CA, Pollack JR, Ross DT, Johnsen H, Akslen LA, Fluge O, Pergamenschikov A, Williams C, Zhu SX, Lonning PE, Borresen-Dale AL, Brown PO, and Botstein D. 2000. Molecular portraits of human breast tumours. Nature 406:747752. $10.1038 / 35021093$

Rhodes DR, Kalyana-Sundaram S, Mahavisno V, Varambally R, Yu J, Briggs BB, Barrette TR, Anstet MJ, Kincead-Beal C, Kulkarni P, Varambally S, Ghosh D, and Chinnaiyan AM. 2007. Oncomine 3.0: genes, pathways, and networks in a collection of 18,000 cancer gene expression profiles. Neoplasia 9:166-180. 10.1593/neo.07112

Rhodes DR, Yu J, Shanker K, Deshpande N, Varambally R, Ghosh D, Barrette T, Pandey A, and Chinnaiyan AM. 2004. ONCOMINE: a cancer microarray database and integrated data-mining platform. Neoplasia 6:1-6. 10.1016/s1476-5586(04)80047-2

Richardson AL, Wang ZC, De Nicolo A, Lu X, Brown M, Miron A, Liao X, Iglehart JD, Livingston DM, and Ganesan S. 2006. X chromosomal abnormalities in basal-like human breast cancer. Cancer Cell 9:121-132. 10.1016/j.ccr.2006.01.013

Sanchez-Carbayo M, Socci ND, Lozano J, Saint F, and Cordon-Cardo C. 2006. Defining molecular profiles of poor outcome in patients with invasive bladder cancer using oligonucleotide microarrays. J Clin Oncol 24:778-789. 10.1200/JCO.2005.03.2375

Scotto L, Narayan G, Nandula SV, Arias-Pulido H, Subramaniyam S, Schneider A, Kaufmann AM, Wright JD, Pothuri B, Mansukhani M, and Murty VV. 2008. Identification of copy number gain and overexpressed genes on chromosome arm $20 \mathrm{q}$ by an integrative genomic approach in cervical cancer: potential role in progression. Genes Chromosomes Cancer 47:755-765. 10.1002/gcc.20577

Sharron Lin X, Hu L, Sandy K, Correll M, Quackenbush J, Wu CL, and Scott McDougal W. 2014. Differentiating progressive from nonprogressive T1 bladder cancer by gene expression profiling: applying RNA-sequencing analysis on archived specimens. Urol Oncol 32:327-336. 10.1016/j.urolonc.2013.06.014

Skrzypczak M, Goryca K, Rubel T, Paziewska A, Mikula M, Jarosz D, Pachlewski J, Oledzki J, and Ostrowski J. 2010. Modeling oncogenic signaling in colon tumors by multidirectional analyses of microarray data directed for maximization of analytical reliability. PLoS One 5. 10.1371/journal.pone.0013091 
684

685

686

687

688

689

690

691

692

693

694

695

696

697

698

699

700

701

702

703

704

705

706

707

708

709

710

711

712

713

714

715

716

717

718

719

720

721

722

723

Song HR, Gonzalez-Gomez I, Suh GS, Commins DL, Sposto R, Gilles FH, Deneen B, and ErdreichEpstein A. 2010. Nuclear factor IA is expressed in astrocytomas and is associated with improved survival. Neuro Oncol 12:122-132. 10.1093/neuonc/nop044

Sorlie T, Perou CM, Tibshirani R, Aas T, Geisler S, Johnsen H, Hastie T, Eisen MB, van de Rijn M, Jeffrey SS, Thorsen T, Quist H, Matese JC, Brown PO, Botstein D, Lonning PE, and BorresenDale AL. 2001. Gene expression patterns of breast carcinomas distinguish tumor subclasses with clinical implications. Proc Natl Acad Sci U S A 98:10869-10874. 10.1073/pnas.191367098

Sorlie T, Tibshirani R, Parker J, Hastie T, Marron JS, Nobel A, Deng S, Johnsen H, Pesich R, Geisler S, Demeter J, Perou CM, Lonning PE, Brown PO, Borresen-Dale AL, and Botstein D. 2003. Repeated observation of breast tumor subtypes in independent gene expression data sets. Proc Natl Acad Sci U S A 100:8418-8423. 10.1073/pnas.0932692100

Stearman RS, Dwyer-Nield L, Zerbe L, Blaine SA, Chan Z, Bunn PA, Jr., Johnson GL, Hirsch FR, Merrick DT, Franklin WA, Baron AE, Keith RL, Nemenoff RA, Malkinson AM, and Geraci MW. 2005. Analysis of orthologous gene expression between human pulmonary adenocarcinoma and a carcinogen-induced murine model. Am J Pathol 167:1763-1775. 10.1016/S0002-9440(10)612576

Stringer BW, Bunt J, Day BW, Barry G, Jamieson PR, Ensbey KS, Bruce ZC, Goasdoue K, Vidal H, Charmsaz S, Smith FM, Cooper LT, Piper M, Boyd AW, and Richards LJ. 2016. Nuclear factor one B (NFIB) encodes a subtype-specific tumour suppressor in glioblastoma. Oncotarget 7:29306-29320. 10.18632/oncotarget.8720

Su H, Hu N, Yang HH, Wang C, Takikita M, Wang QH, Giffen C, Clifford R, Hewitt SM, Shou JZ, Goldstein AM, Lee MP, and Taylor PR. 2011. Global gene expression profiling and validation in esophageal squamous cell carcinoma and its association with clinical phenotypes. Clin Cancer Res 17:2955-2966. 10.1158/1078-0432.CCR-10-2724

Suzuki H, Aoki K, Chiba K, Sato Y, Shiozawa Y, Shiraishi Y, Shimamura T, Niida A, Motomura K, Ohka F, Yamamoto T, Tanahashi K, Ranjit M, Wakabayashi T, Yoshizato T, Kataoka K, Yoshida K, Nagata Y, Sato-Otsubo A, Tanaka H, Sanada M, Kondo Y, Nakamura H, Mizoguchi M, Abe T, Muragaki Y, Watanabe R, Ito I, Miyano S, Natsume A, and Ogawa S. 2015. Mutational landscape and clonal architecture in grade II and III gliomas. Nat Genet 47:458-468. 10.1038/ng.3273

Tomlins SA, Mehra R, Rhodes DR, Cao X, Wang L, Dhanasekaran SM, Kalyana-Sundaram S, Wei JT, Rubin MA, Pienta KJ, Shah RB, and Chinnaiyan AM. 2007. Integrative molecular concept modeling of prostate cancer progression. Nat Genet 39:41-51. 10.1038/ng1935

Turashvili G, Bouchal J, Baumforth K, Wei W, Dziechciarkova M, Ehrmann J, Klein J, Fridman E, Skarda J, Srovnal J, Hajduch M, Murray P, and Kolar Z. 2007. Novel markers for differentiation of lobular and ductal invasive breast carcinomas by laser microdissection and microarray analysis. BMC Cancer 7:55. 10.1186/1471-2407-7-55

Varambally S, Yu J, Laxman B, Rhodes DR, Mehra R, Tomlins SA, Shah RB, Chandran U, Monzon FA, Becich MJ, Wei JT, Pienta KJ, Ghosh D, Rubin MA, and Chinnaiyan AM. 2005. Integrative genomic and proteomic analysis of prostate cancer reveals signatures of metastatic progression. Cancer Cell 8:393-406. 10.1016/j.ccr.2005.10.001

Peer) reviewing PDF | (2019:06:38719:2:0:NEW 18 Feb 2020) 
724

725

726

727

728

729

730

731

732

733

734

735

736

737

738

739

740

741

742

743

744

745

746

747

748

749

750
Wachi S, Yoneda K, and Wu R. 2005. Interactome-transcriptome analysis reveals the high centrality of genes differentially expressed in lung cancer tissues. Bioinformatics 21:4205-4208.

10.1093/bioinformatics/bti688

Wallace TA, Prueitt RL, Yi M, Howe TM, Gillespie JW, Yfantis HG, Stephens RM, Caporaso NE, Loffredo CA, and Ambs S. 2008. Tumor immunobiological differences in prostate cancer between AfricanAmerican and European-American men. Cancer Res 68:927-936. 10.1158/0008-5472.CAN-072608

Wurmbach E, Chen YB, Khitrov G, Zhang W, Roayaie S, Schwartz M, Fiel I, Thung S, Mazzaferro V, Bruix J, Bottinger E, Friedman S, Waxman S, and Llovet JM. 2007. Genome-wide molecular profiles of HCV-induced dysplasia and hepatocellular carcinoma. Hepatology 45:938-947. 10.1002/hep.21622

Yang B, Zhou ZH, Chen L, Cui X, Hou JY, Fan KJ, Han SH, Li P, Yi SQ, and Liu Y. 2018. Prognostic significance of NFIA and NFIB in esophageal squamous carcinoma and esophagogastric junction adenocarcinoma. Cancer Med 7:1756-1765. 10.1002/cam4.1434

Ye H, Yu T, Temam S, Ziober BL, Wang J, Schwartz JL, Mao L, Wong DT, and Zhou X. 2008. Transcriptomic dissection of tongue squamous cell carcinoma. BMC Genomics 9:69. 10.1186/1471-2164-9-69

Yusenko MV, Kuiper RP, Boethe T, Ljungberg B, van Kessel AG, and Kovacs G. 2009. High-resolution DNA copy number and gene expression analyses distinguish chromophobe renal cell carcinomas and renal oncocytomas. BMC Cancer 9:152. 10.1186/1471-2407-9-152

Zhai Y, Kuick R, Nan B, Ota I, Weiss SJ, Trimble CL, Fearon ER, and Cho KR. 2007. Gene expression analysis of preinvasive and invasive cervical squamous cell carcinomas identifies HOXC10 as a key mediator of invasion. Cancer Res 67:10163-10172. 10.1158/0008-5472.CAN-07-2056

Zhao H, Langerod A, Ji Y, Nowels KW, Nesland JM, Tibshirani R, Bukholm IK, Karesen R, Botstein D, Borresen-Dale AL, and Jeffrey SS. 2004. Different gene expression patterns in invasive lobular and ductal carcinomas of the breast. Mol Biol Cell 15:2523-2536. 10.1091/mbc.e03-11-0786 


\section{Figure 1}

The transcription levels of the NFI family members in different types of human cancers.

Notes: The figure is generated from ONCOMINE with extract thresholds ( $p$-value: 0.01 ; fold change: 2 ; gene rank: 10\%). The cell number represents the dataset number that meets all of the thresholds with the color blue for underexpression and color red for overexpression. Cell color is determined by the best gene rank percentile for the analyses within the cell.

Abbreviations: NFI, Nuclear factor I; CNS, central nervous system. 


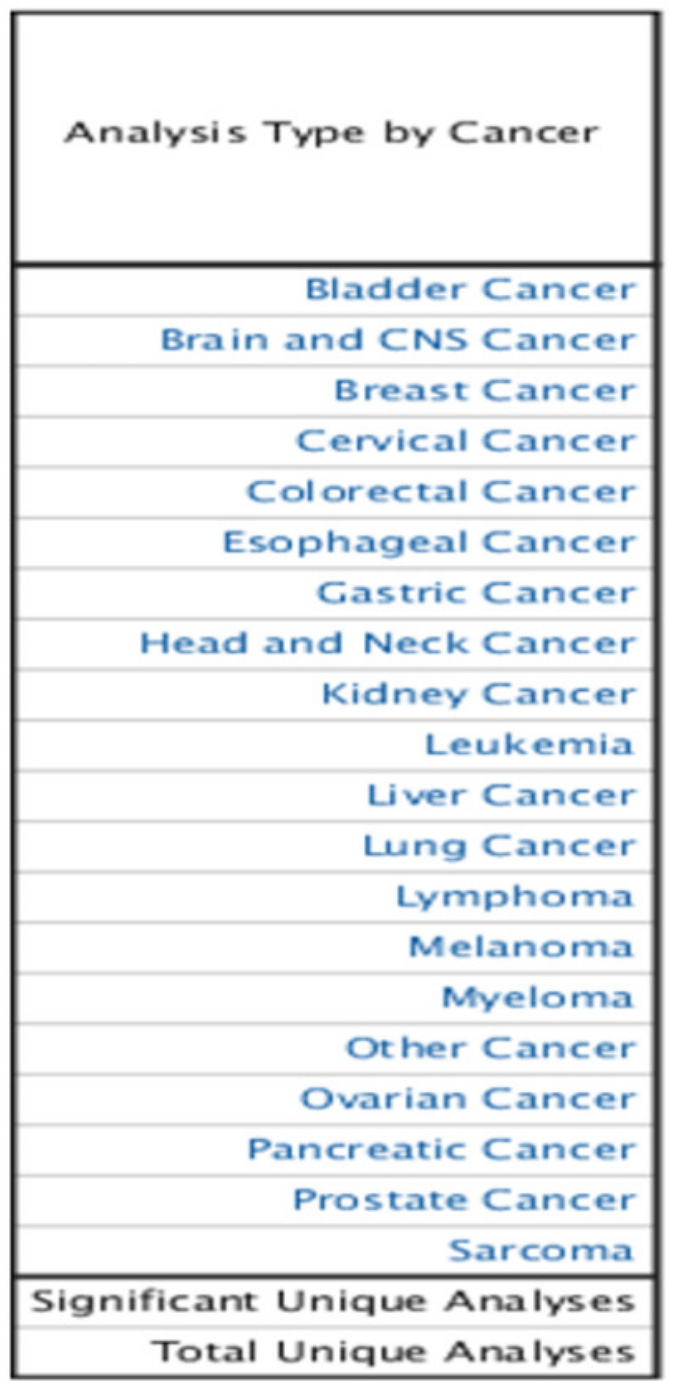

\begin{tabular}{|c|c|c|c|c|c|c|c|}
\hline \multicolumn{2}{|c|}{$\begin{array}{l}\text { Cancer } \\
\text { vs. } \\
\text { Normal } \\
\text { NFIA }\end{array}$} & \multicolumn{2}{|c|}{$\begin{array}{l}\text { Cancer } \\
\text { vs. } \\
\text { Normal } \\
\text { NFIB }\end{array}$} & \multicolumn{2}{|c|}{$\begin{array}{l}\text { Cancer } \\
\text { vor. } \\
\text { Normal } \\
\text { NFIC }\end{array}$} & \multicolumn{2}{|c|}{$\begin{array}{l}\text { Cancer } \\
\text { vs. } \\
\text { Normal } \\
\text { NFIX }\end{array}$} \\
\hline & 2 & & 3 & & 3 & & 1 \\
\hline 6 & 3 & 9 & 1 & & & 5 & \\
\hline \multirow[t]{2}{*}{1} & 12 & 1 & 22 & & 2 & & 8 \\
\hline & & & 2 & & 1 & & \\
\hline \multirow[t]{4}{*}{2} & 2 & 1 & 1 & & & & \\
\hline & 3 & & & & & 2 & 2 \\
\hline & & 1 & & & & & $\mathbf{1}$ \\
\hline & 3 & 1 & 3 & & & & 2 \\
\hline \multirow[t]{3}{*}{1} & & 2 & 3 & & & & \\
\hline & 9 & 2 & 1 & & 2 & & \\
\hline & 3 & & & & & & \\
\hline 2 & 6 & & 7 & & 2 & & 1 \\
\hline \multirow[t]{7}{*}{4} & 4 & 10 & 1 & 4 & & & \\
\hline & 2 & 1 & 4 & 2 & 1 & 1 & 2 \\
\hline & 2 & 3 & 3 & & 3 & & 2 \\
\hline & 1 & & 5 & & & & \\
\hline & 1 & & 1 & & 1 & & 2 \\
\hline & & 1 & 1 & & 1 & 1 & 1 \\
\hline & & 3 & 1 & & 2 & 1 & \\
\hline 16 & 53 & 34 & 59 & 6 & 18 & 10 & 22 \\
\hline \multicolumn{2}{|c|}{312} & \multicolumn{2}{|c|}{449} & \multicolumn{2}{|c|}{438} & \multicolumn{2}{|c|}{457} \\
\hline
\end{tabular}

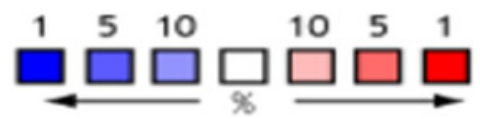




\section{Figure 2}

Transcription levels, genomic analysis of the NFIs and regression analysis between the mRNA expression of the NFIs and its corresponding methylation in breast cancer (A-G).

Notes: Box-whisker plots show the differences in transcript levels of the NFI family members between normal and tumors samples. The median value is represented by the middle line in the boxes. Statistical differences were examined by two tailed student's t-test. $* * * * p<0.0001, * * * p<0.001$

Abbreviations: NFI, Nuclear factor I ; TCGA, The Cancer Genome Atlas. 
A

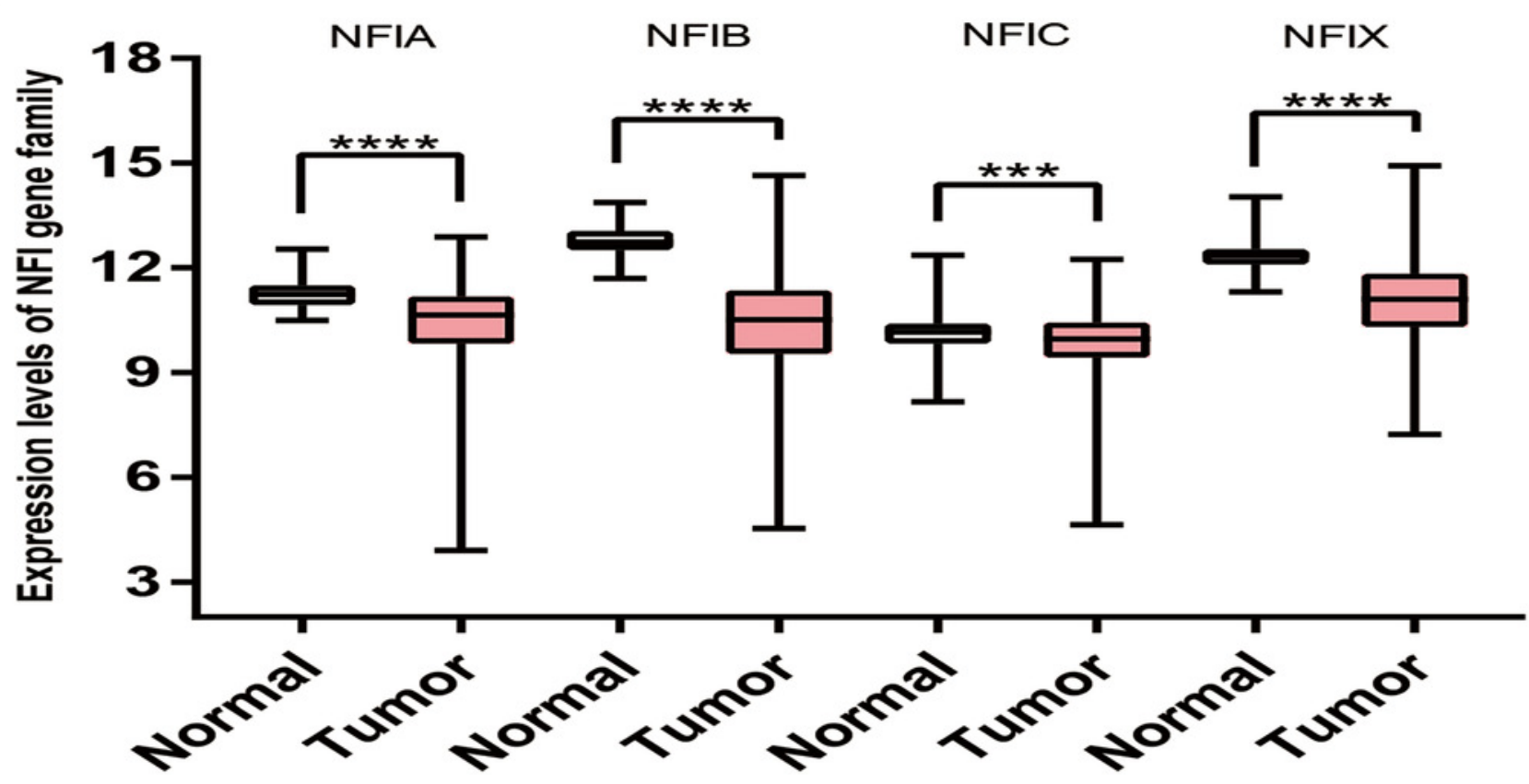

B

C
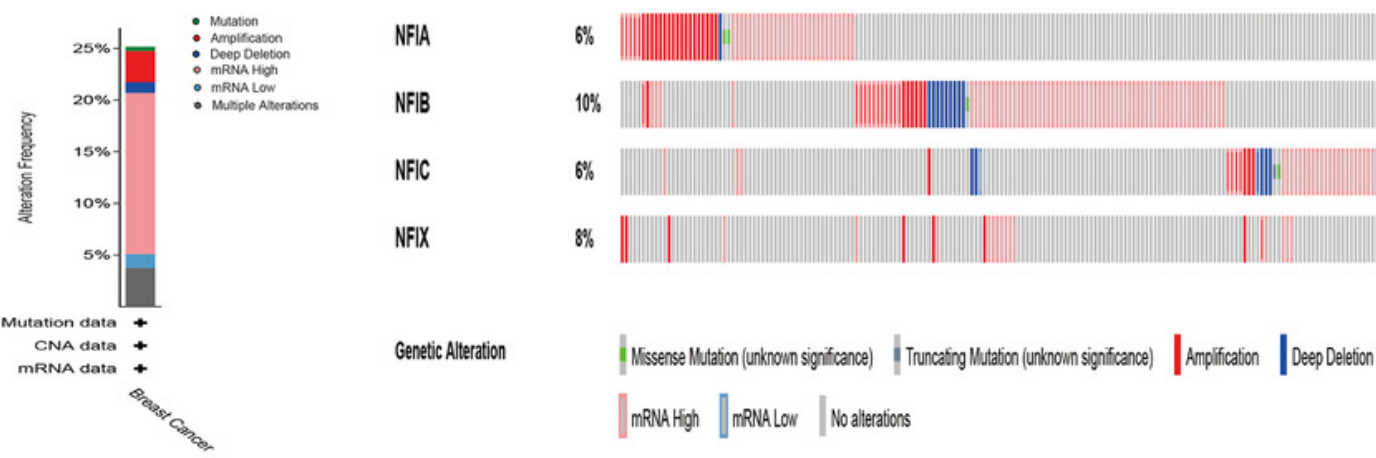

D

E
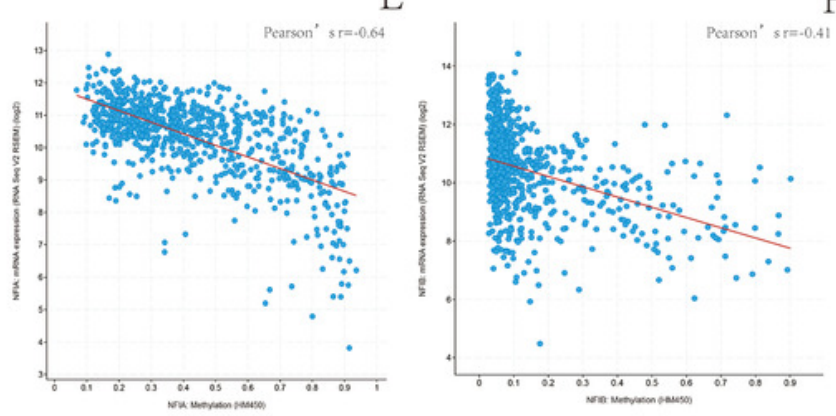

F

G
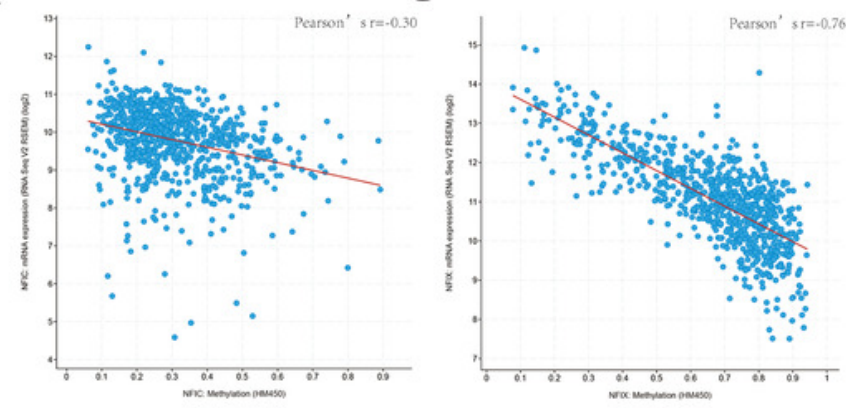


\section{Figure 3}

Transcription levels, genomic analysis of the NFIs and regression analysis between the mRNA expression of the NFIs and its corresponding methylation in lung cancer (A-M).

Notes: Box-whisker plots show the differences in transcript levels of the NFI family members between normal and tumors samples. The median value is represented by the middle line in the boxes. Statistical differences were examined by two tailed student's t-test. $* * * p<0.0001$.

Abbreviations: NFI, Nuclear factor I; TCGA, The Cancer Genome Atlas. 
A

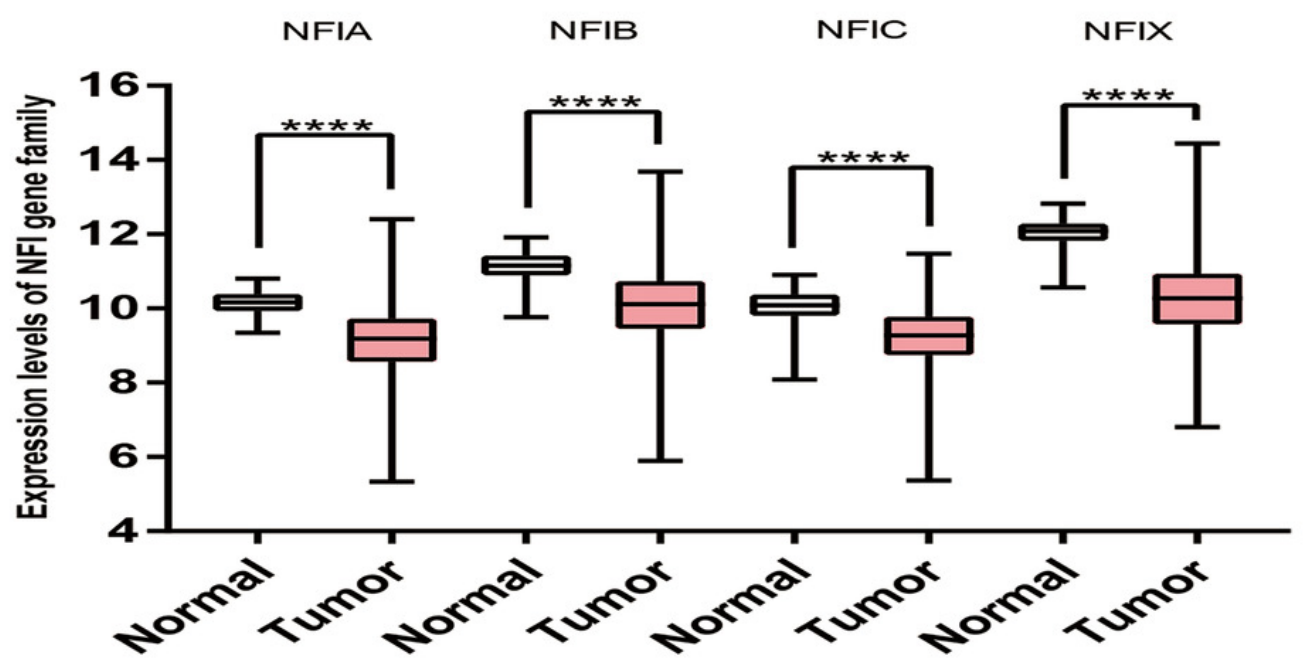

B

C

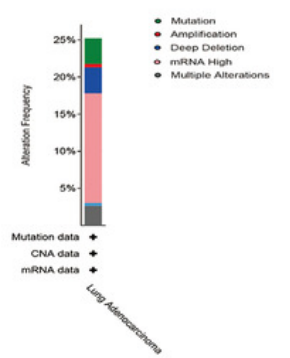

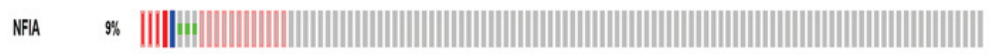

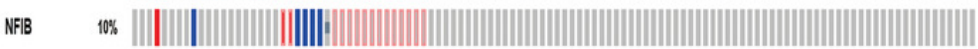

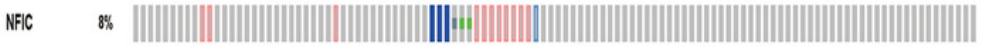

NFx $\quad 3 \% \quad|||||||||||||||||||||||||||||||||||||||||||||||||||||||||||||||||||||||||||||||||||||||||||||||||||||| \mid$

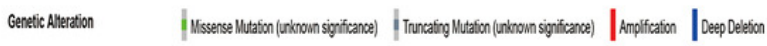
|mPVaHght |mRValow | No aleadions
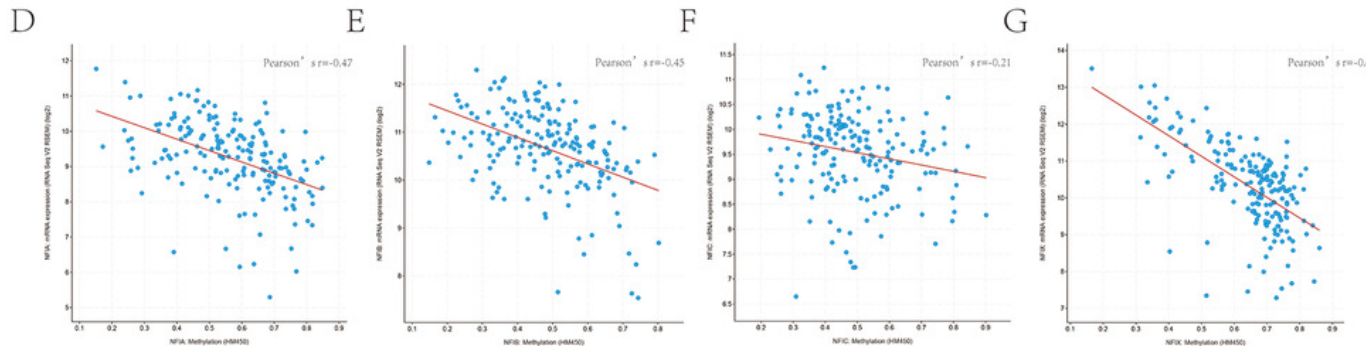

$\mathrm{H}$
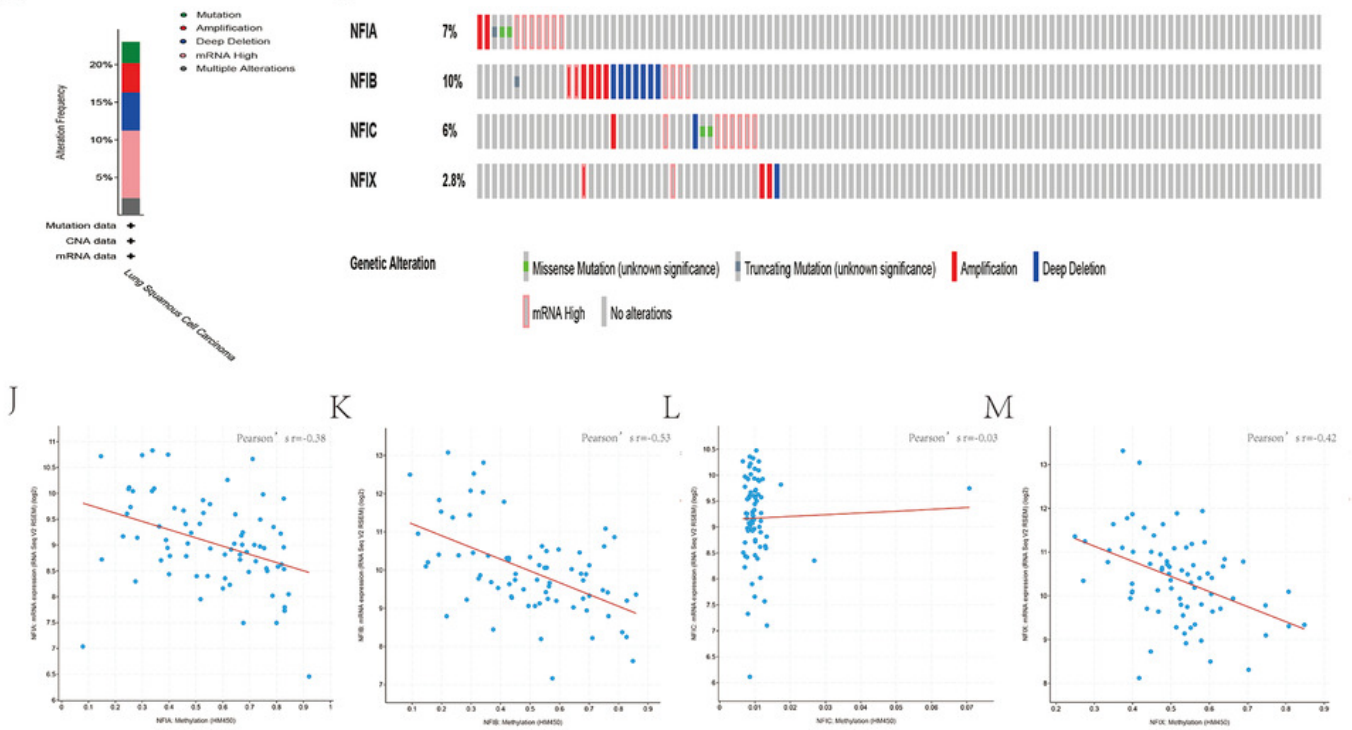


\section{Figure 4}

Transcription levels, genomic analysis of the NFIs and regression analysis between the mRNA expression of the NFIs and its corresponding methylation in bladder cancer (A-G).

Notes: Box-whisker plots show the differences in transcript levels of the NFI family members between normal and tumors samples. The median value is represented by the middle line in the boxes. Statistical differences were examined by two tailed student's t-test. $* * * p<0.0001$.

Abbreviations: NFI, Nuclear factor I; TCGA, The Cancer Genome Atlas. 
A

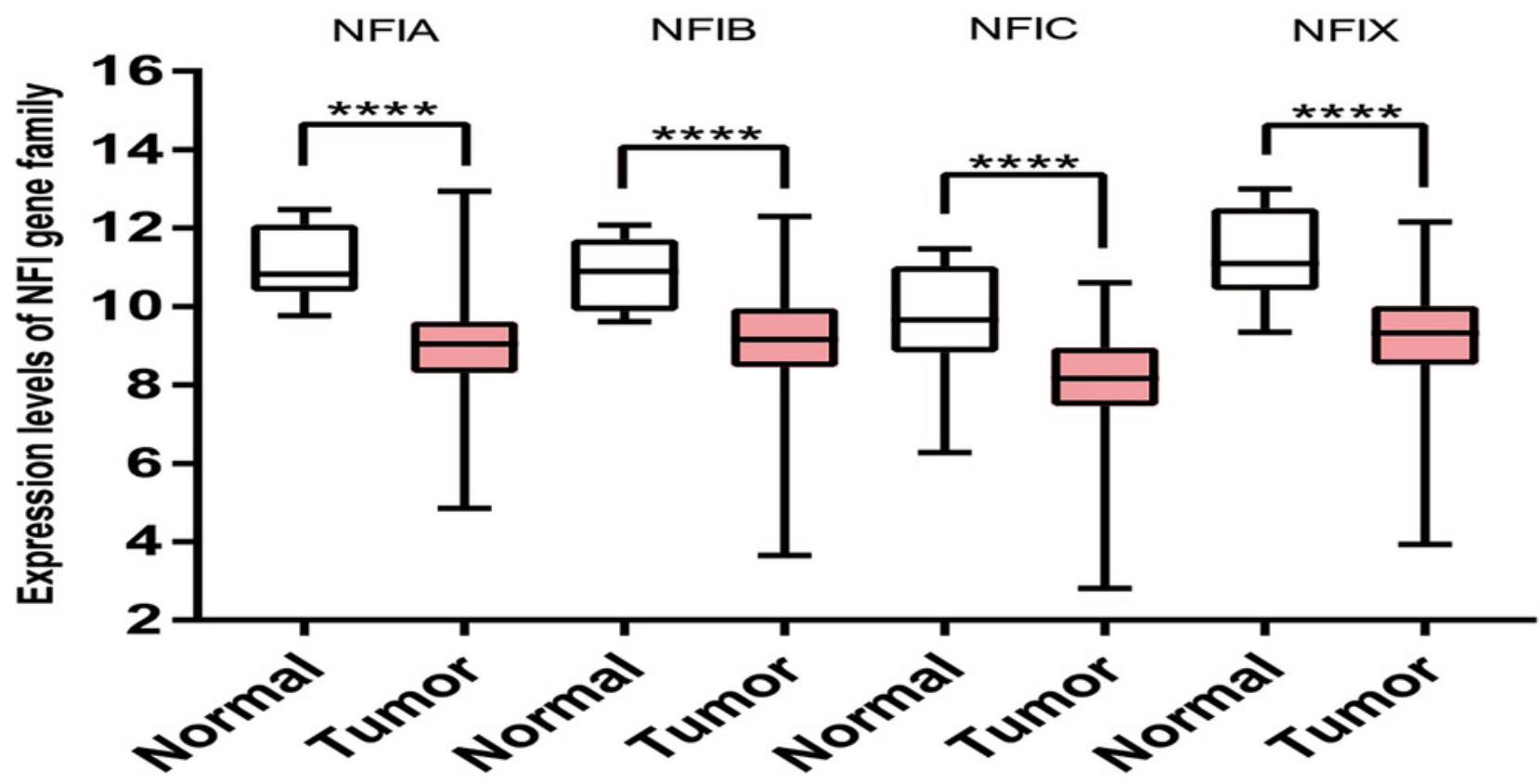

B

C.
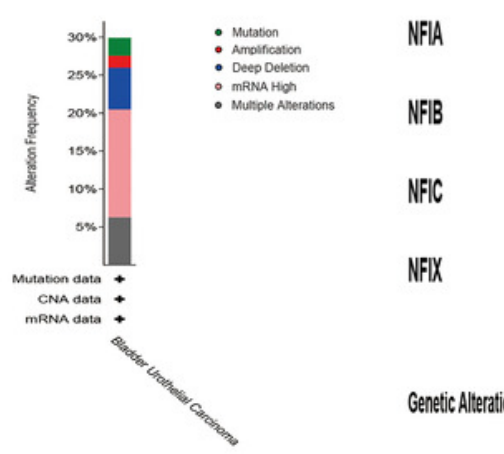

8"

$17 \%$

$6 \%$

$5 \%$

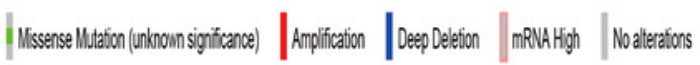

E

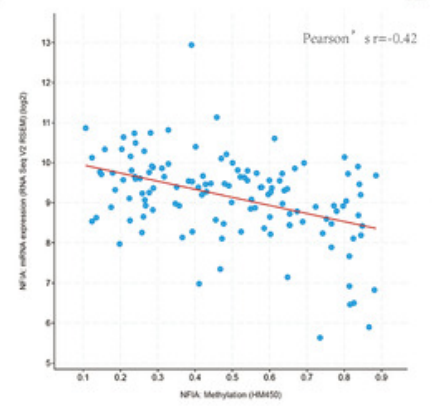

D

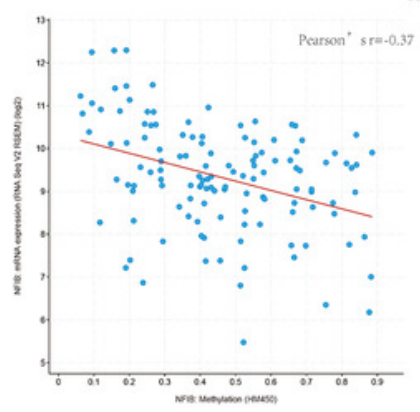

F

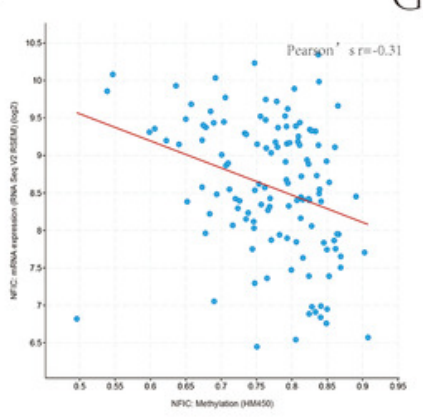

G

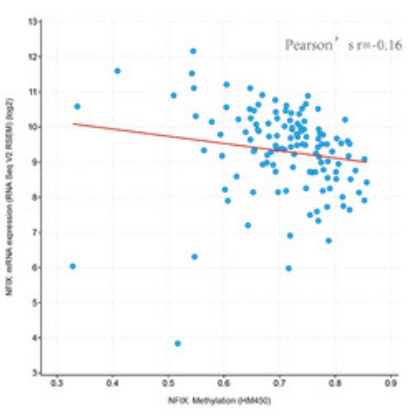




\section{Figure 5}

Transcription levels, genomic analysis of the NFIs and regression analysis between the mRNA expression of the NFIs and its corresponding methylation in head-neck cancer (A$\mathrm{G)}$.

Notes: Box-whisker plots show the differences in transcript levels of the NFI family members between normal and tumors samples. The median value is represented by the middle line in the boxes. Statistical differences were examined by two tailed student's $t$-test. $* * * p<0.0001$.

Abbreviations: NFI, Nuclear factor I; TCGA, The Cancer Genome Atlas. 
A

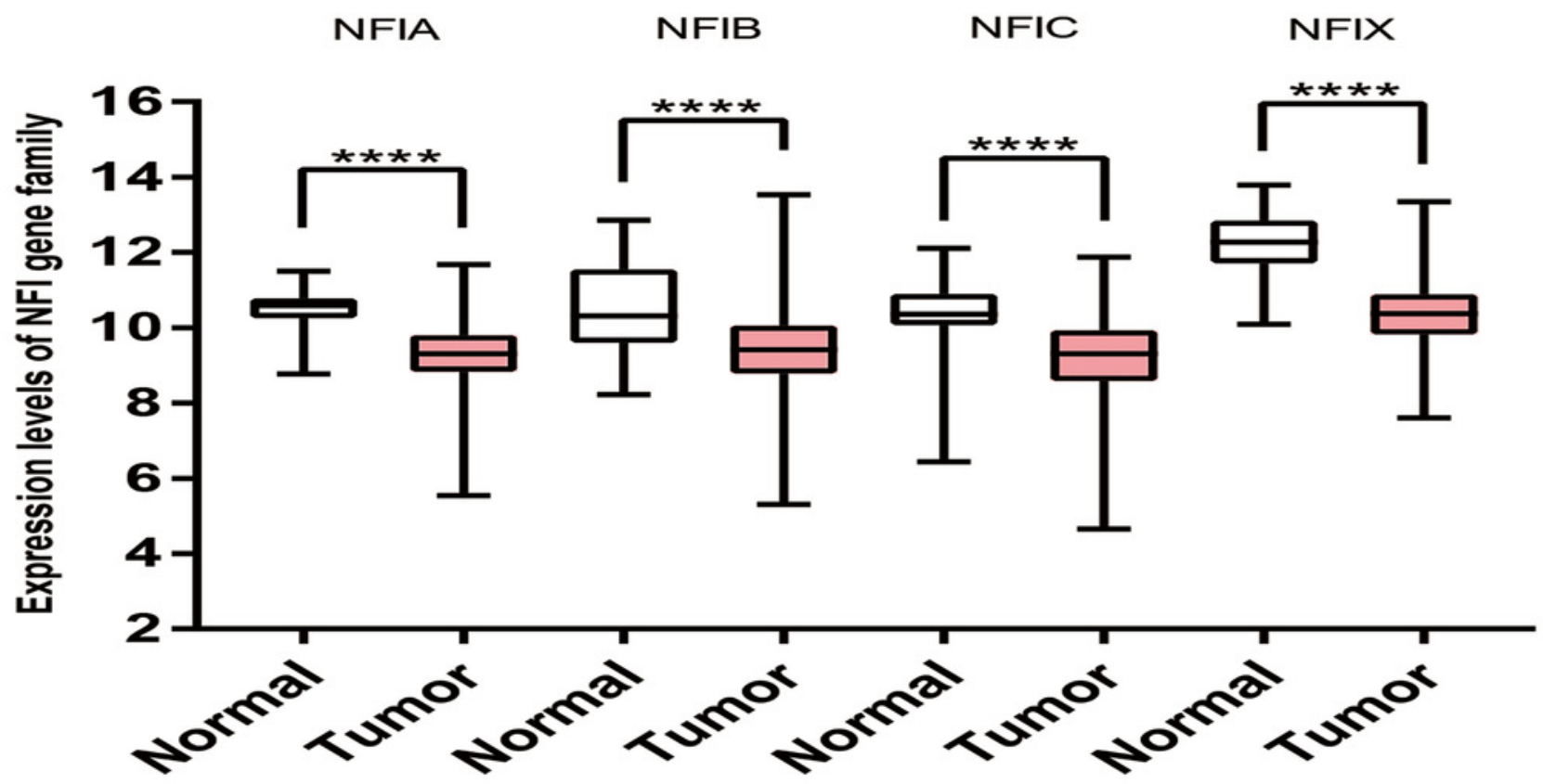

B

C

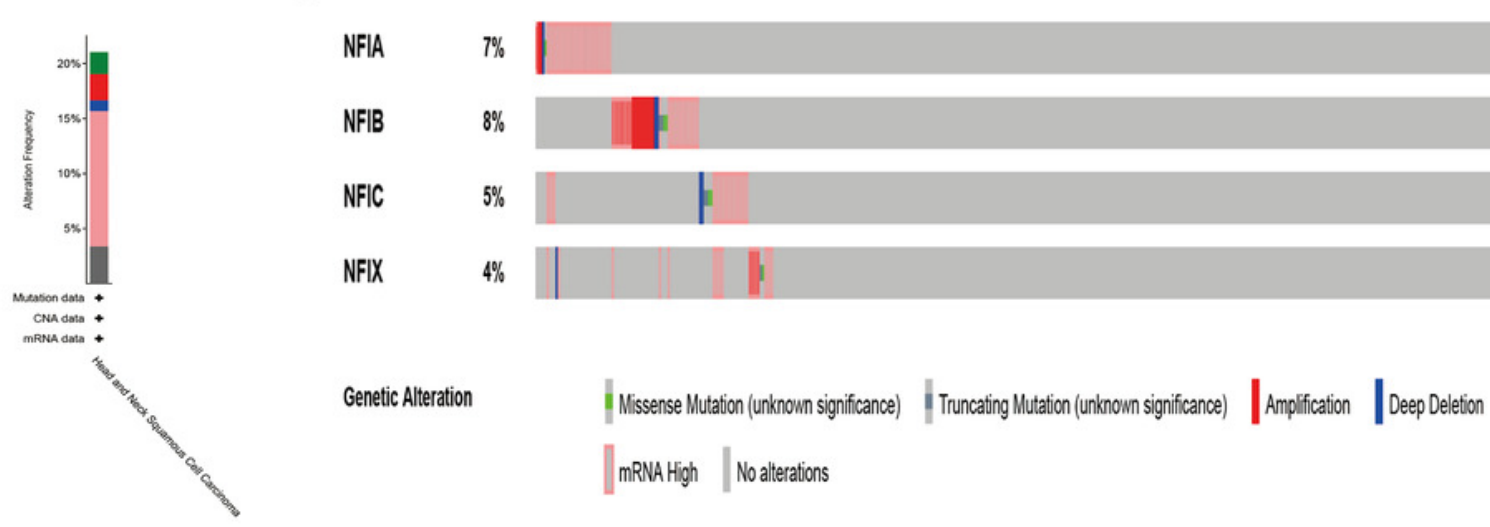

D

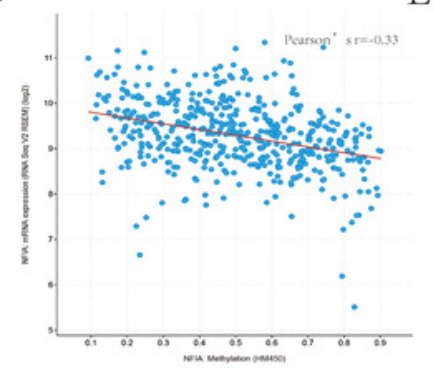

E

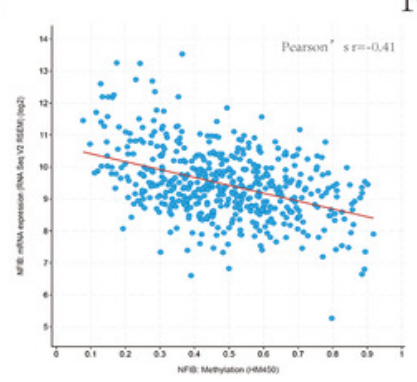

F

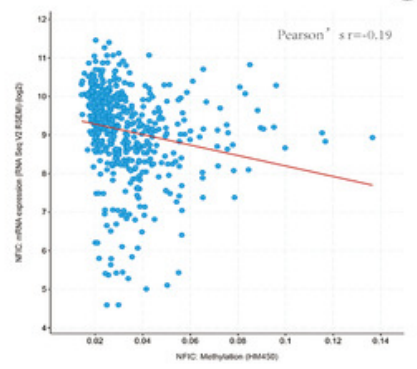

G

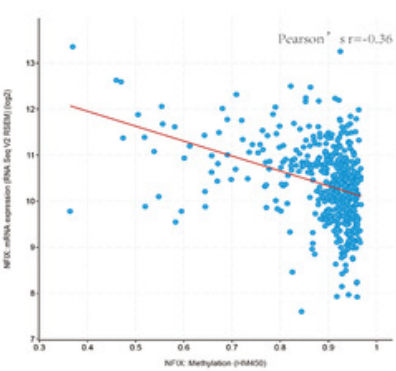




\section{Figure 6}

Transcription levels, genomic analysis of the NFIs and regression analysis between the mRNA expression of the NFIs and its corresponding methylation in esophageal cancer (A-G).

Notes: Box-whisker plots show the differences in transcript levels of the NFI family members between normal and tumors samples. The median value is represented by the middle line in the boxes. Statistical differences were examined by two tailed student's t-test. ${ }^{* * *} p<0.0001, * * p<0.01$.

Abbreviations: NFI, Nuclear factor I; TCGA, The Cancer Genome Atlas. 
A

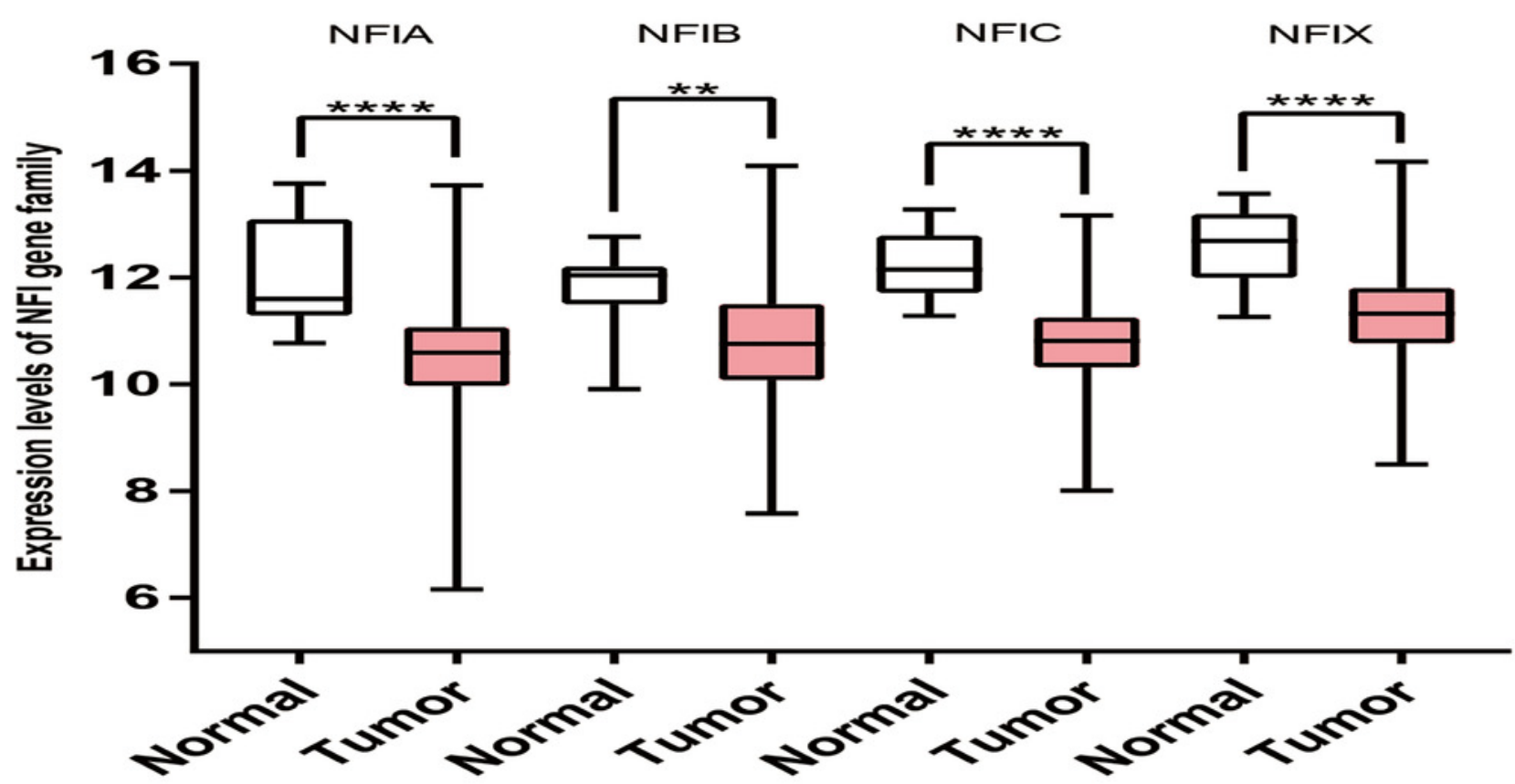

B

C

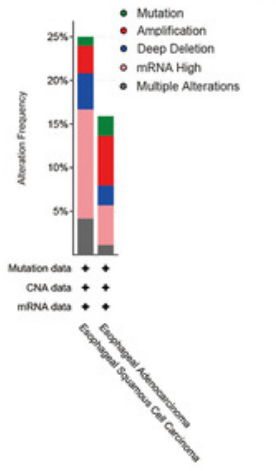

NFIA $\quad 7$

$7 \% \quad|\||\||$

NFIB

$8 \%$

NFIC

$5 \%$

NFIX

$9 \%$

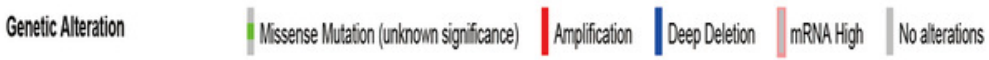

D

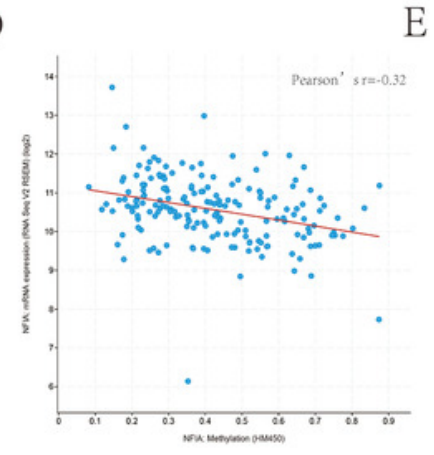

E

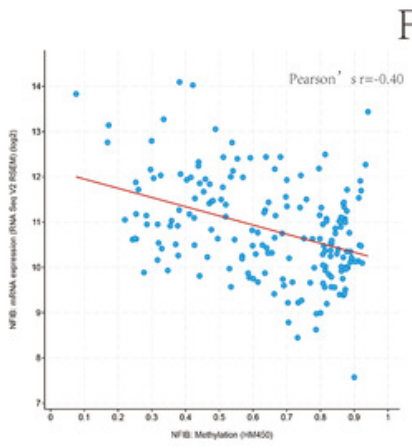

F

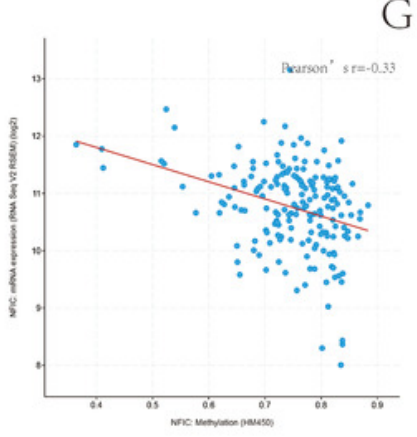

G

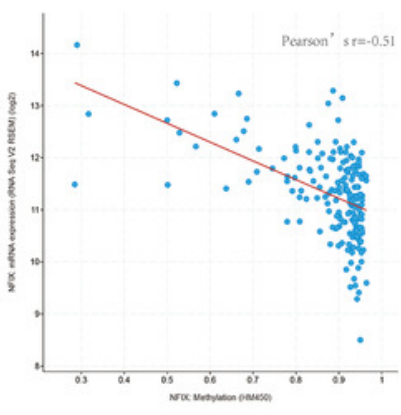




\section{Figure 7}

Transcription levels, genomic analysis of the NFIs and regression analysis between the mRNA expression of the NFIs and its corresponding methylation in kidney chromophobe cell carcinoma (A-G).

Notes: Box-whisker plots show the differences in transcript levels of the NFI family members between normal and tumors samples. The median value is represented by the middle line in the boxes. Statistical differences were examined by two tailed student's $t$-test. ${ }^{* * *} p<0.0001, * p<0.05$, ns-non significant.

Abbreviations: NFI, Nuclear factor I; TCGA, The Cancer Genome Atlas. 
A

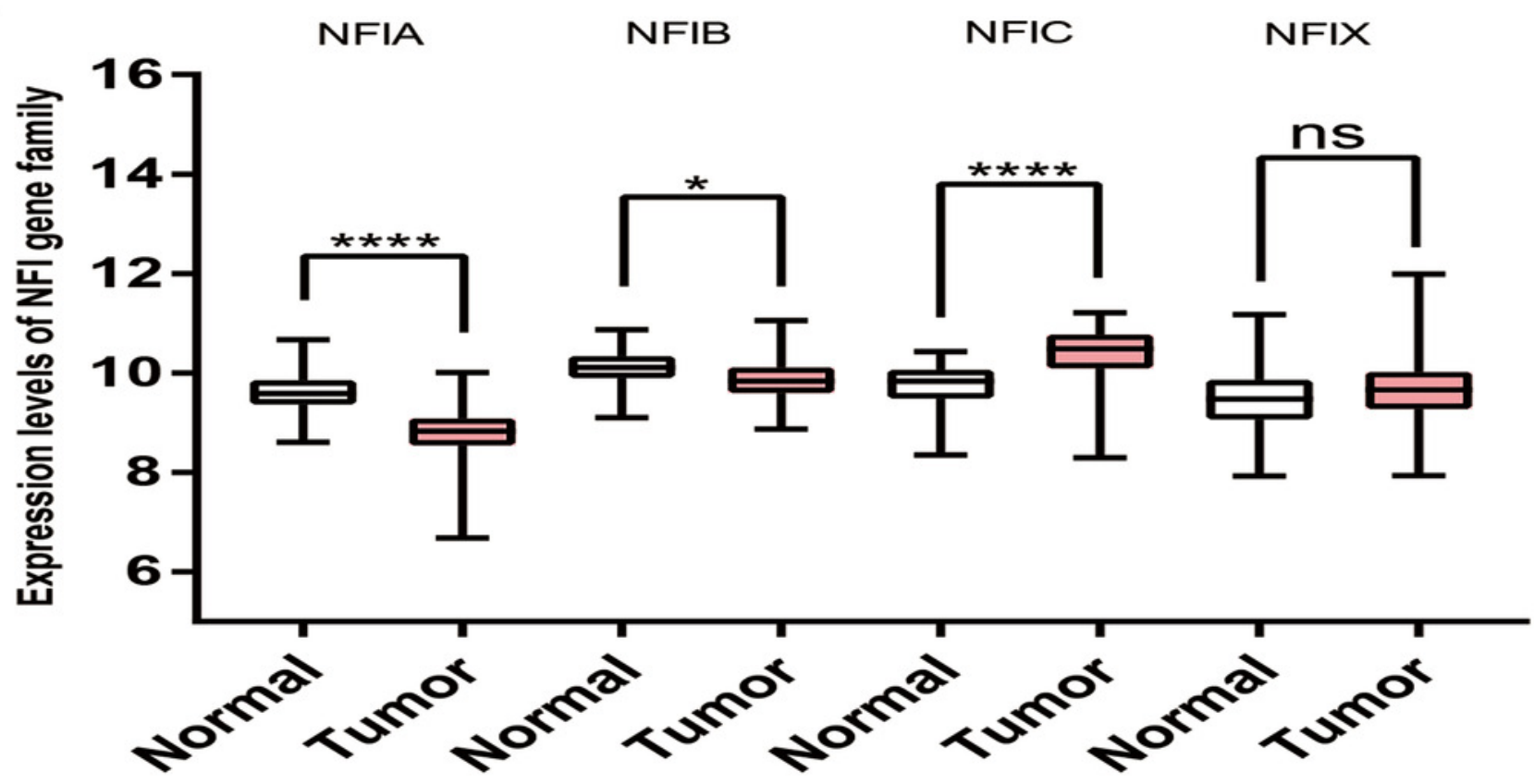

B

C
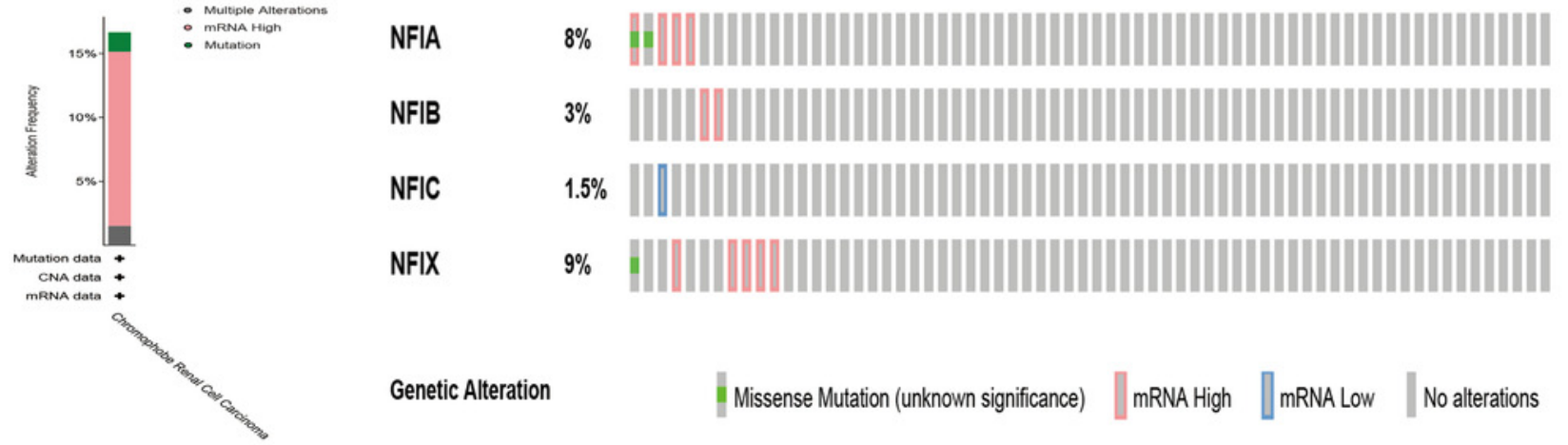

D

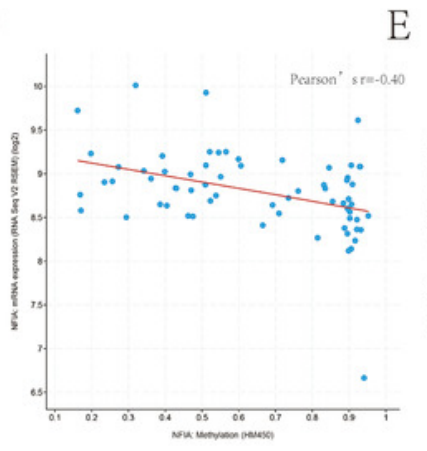

E

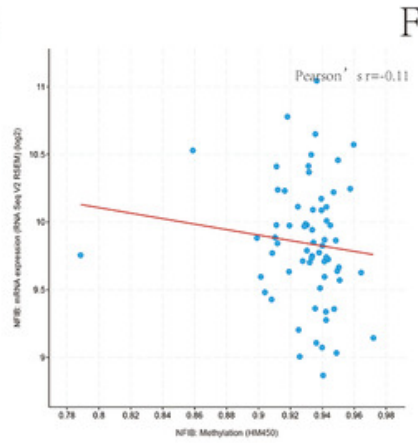

F

G
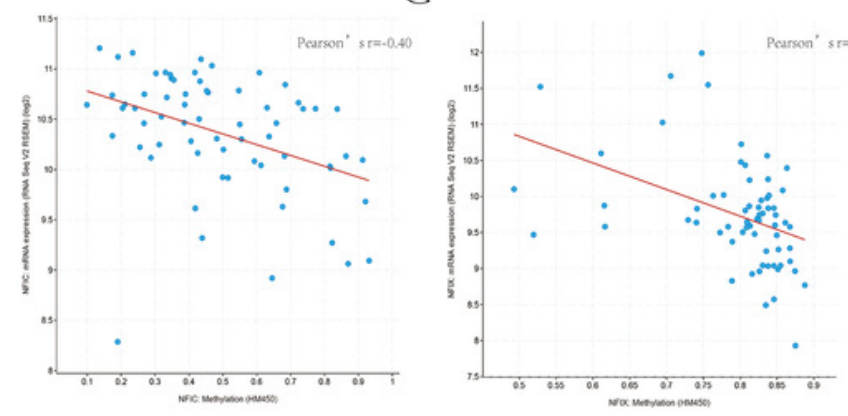


\section{Figure 8}

Transcription levels, genomic analysis of the NFIs and regression analysis between the mRNA expression of the NFIs and its corresponding methylation in kidney renal clear cell carcinoma (A-G).

Notes: Box-whisker plots show the differences in transcript levels of the NFI family members between normal and tumors samples. The median value is represented by the middle line in the boxes. Statistical differences were examined by two tailed student's $t$-test. ${ }^{* * *} p<0.0001,{ }^{* *} p<0.001$.

Abbreviations: NFI, Nuclear factor I; TCGA, The Cancer Genome Atlas. 
A

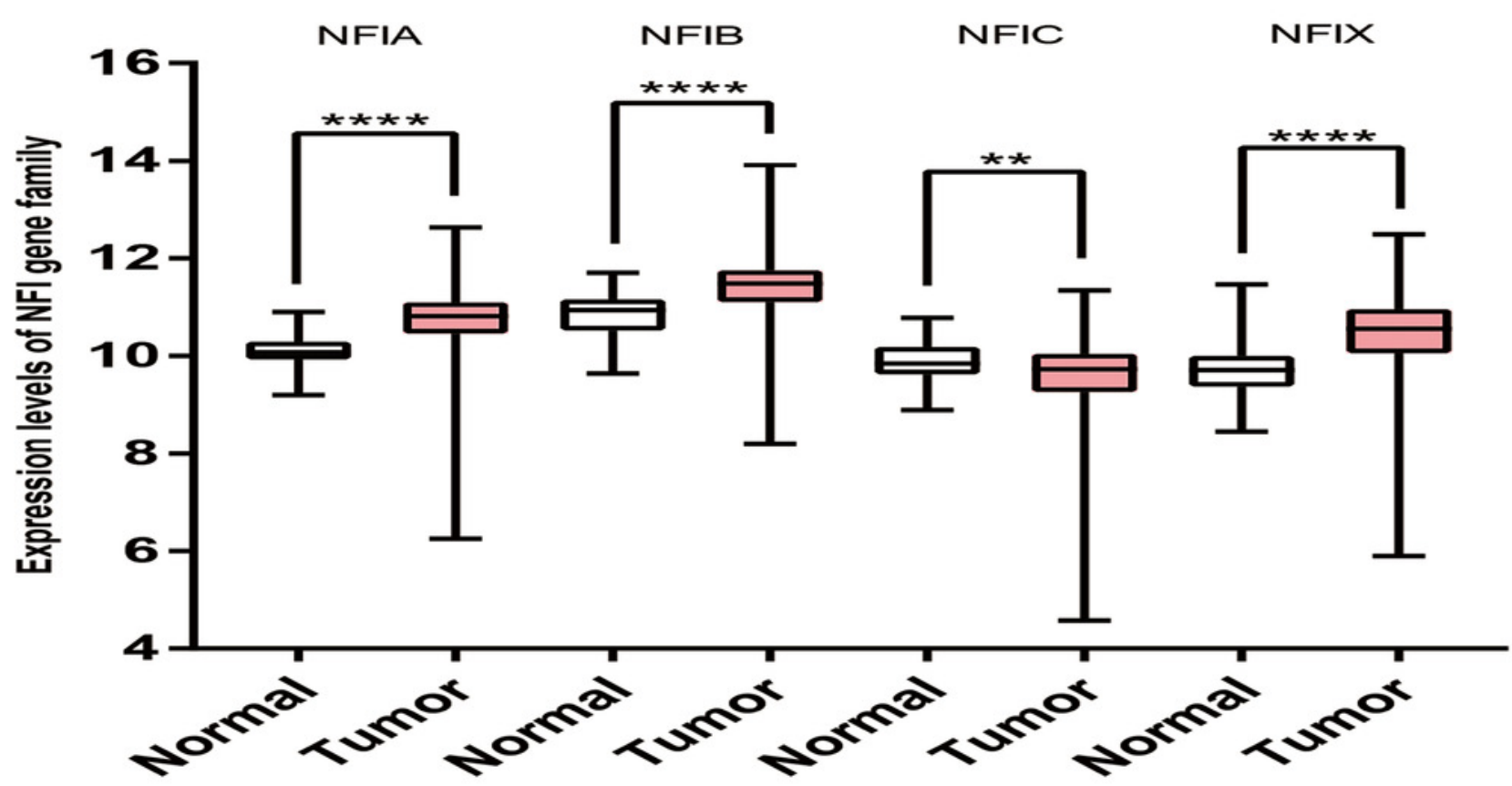

B

C
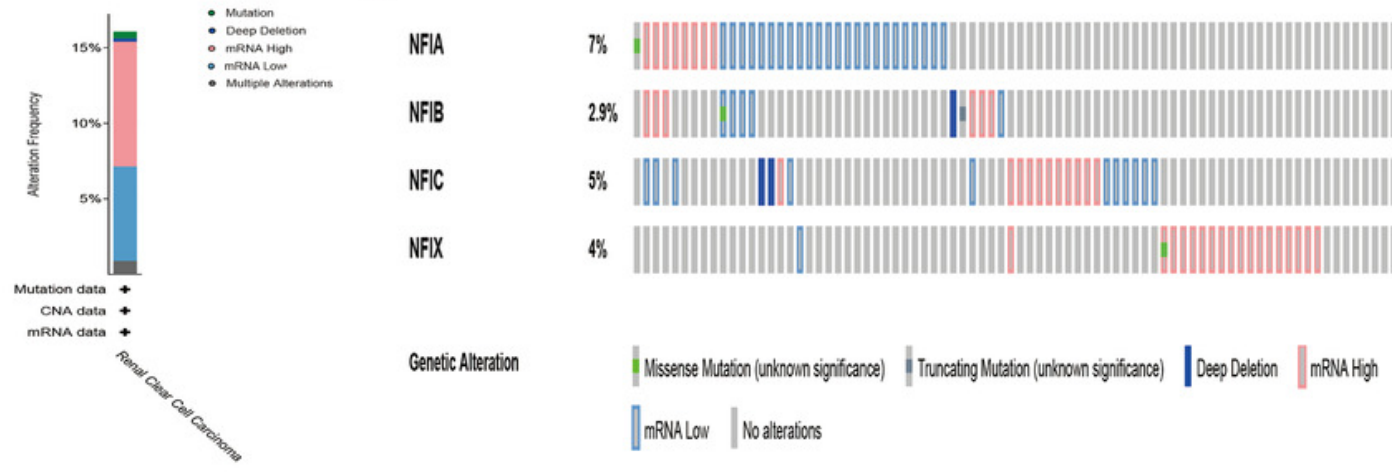

$\mathrm{D}$

E

F

G
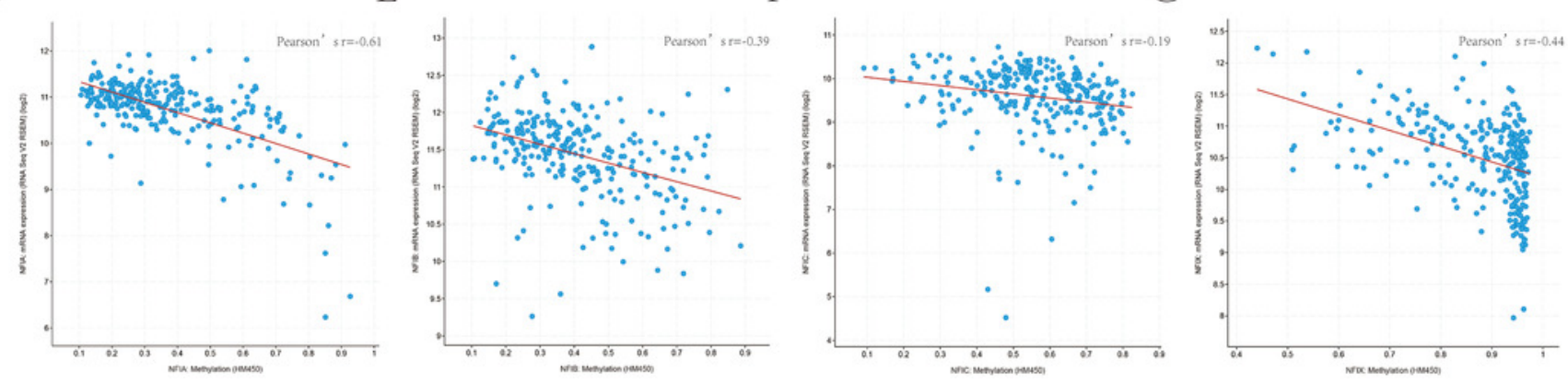


\section{Figure 9}

Transcription levels, genomic analysis of the NFIs and regression analysis between the mRNA expression of the NFIs and its corresponding methylation in kidney renal papillary cell carcinoma (A-G).

Notes: Box-whisker plots show the differences in transcript levels of the NFI family members between normal and tumors samples. The median value is represented by the middle line in the boxes. Statistical differences were examined by two tailed student's t-test. ${ }^{* * *} p<0.0001, * * p<0.01$.

Abbreviations: NFI, Nuclear factor I; TCGA, The Cancer Genome Atlas. 
A

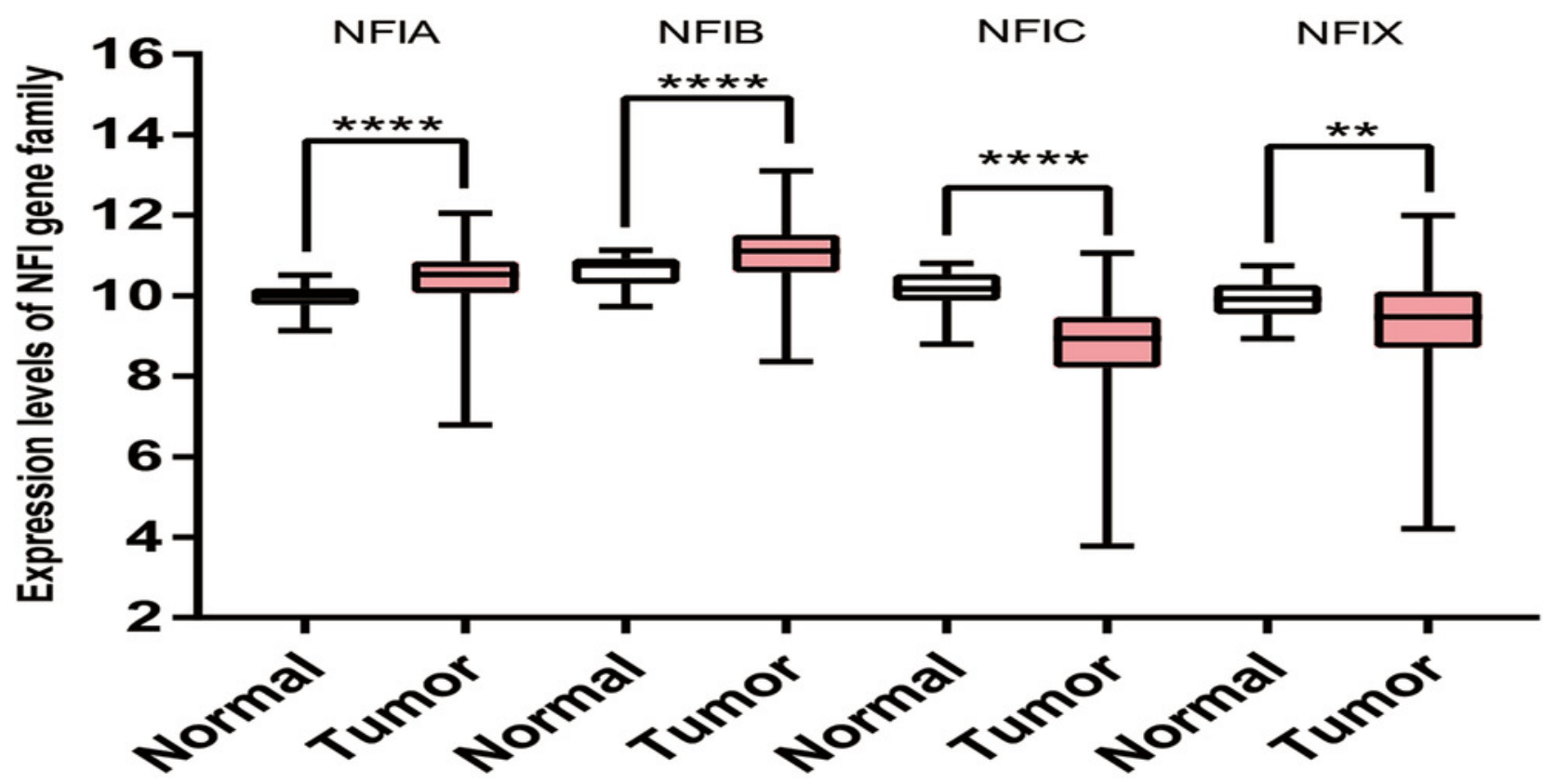

B

C

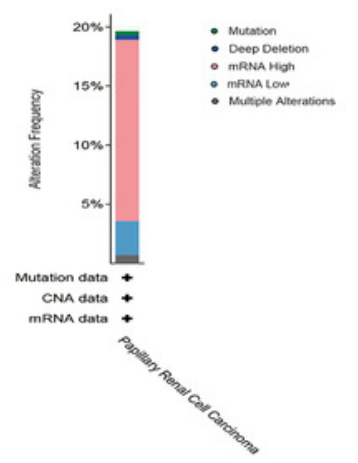

$\begin{array}{ll}\text { NFIA } & 7 \% \\ \text { NFIB } & 25 \% \\ \text { NFIC } & 6 \% \\ \text { NFIX } & 7 \%\end{array}$

Genetic Alteration | Missense Mutation (unknown significance) | Deep Deletion $\mid$ mRNA High $\mid$ mRNA Low $\mid$ No alterations

C

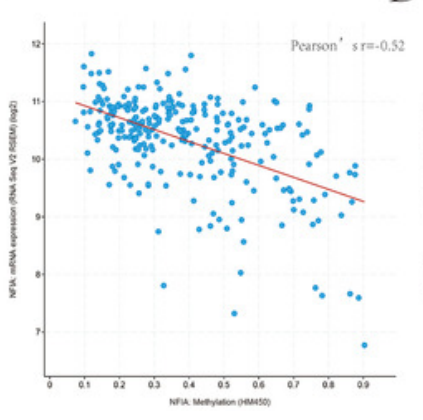

D

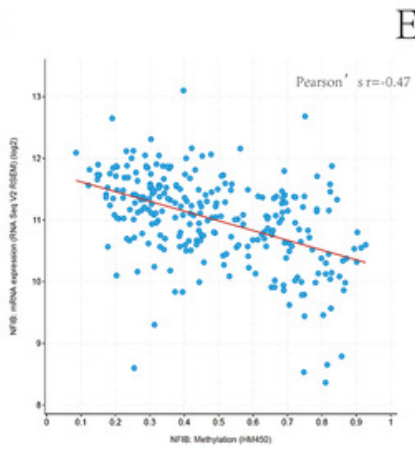

E

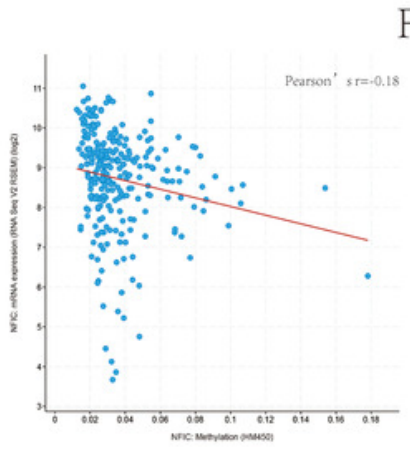

F

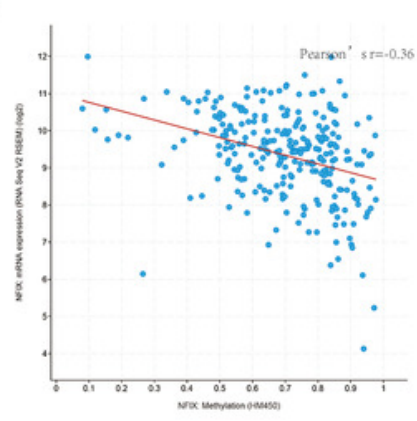




\section{Table 1 (on next page)}

Datasets of the NFI family in breast cancer (ONCOMINE database) 


\begin{tabular}{|c|c|c|c|c|c|c|}
\hline Gene & Dataset & Normaln cases [ & Tumorn cases $\rrbracket$ & Fold change & $t$-test & $p$-value \\
\hline \multirow[t]{13}{*}{ NFIA } & Karnoub & Breast (15) & Invasive Ductal Breast Carcinoma (7) & -3.381 & -7.532 & $1.09 \mathrm{E}-06$ \\
\hline & Richardson 2 & Breast (7) & Ductal Breast Carcinoma (40) & -6.061 & -7.225 & $2.40 \mathrm{E}-09$ \\
\hline & \multirow[t]{7}{*}{ Curtis } & \multirow[t]{7}{*}{ Breast (144) } & Ductal Breast Carcinoma in Situ (10) & -2.207 & -9.411 & $8.54 \mathrm{E}-07$ \\
\hline & & & Invasive Ductal Breast Carcinoma $(1,556)$ & -2.017 & -26.559 & $4.91 \mathrm{E}-69$ \\
\hline & & & Invasive Breast Carcinoma (21) & -2.292 & -8.448 & $9.48 \mathrm{E}-09$ \\
\hline & & & Medullary Breast Carcinoma (32) & -3.457 & -14.097 & $4.20 \mathrm{E}-17$ \\
\hline & & & Tubular Breast Carcinoma (67) & -2.039 & -15.725 & $3.61 \mathrm{E}-31$ \\
\hline & & & Mucinous Breast Carcinoma (46) & -2.227 & -14.215 & $4.25 \mathrm{E}-22$ \\
\hline & & & Breast Carcinoma (14) & -2.137 & -6.042 & $1.51 \mathrm{E}-05$ \\
\hline & \multirow[t]{2}{*}{ TCGA } & \multirow[t]{2}{*}{ Breast (61) } & Invasive Ductal Breast Carcinoma (389) & -2.277 & -11.49 & 7.00E-22 \\
\hline & & & Mucinous Breast Carcinoma (4) & -2.851 & -10.414 & $1.96 \mathrm{E}-05$ \\
\hline & Gluck & Breast (4) & Invasive Breast Carcinoma (154) & -2.207 & -6.408 & $4.27 \mathrm{E}-04$ \\
\hline & Finak & Breast (6) & Invasive Breast Carcinoma (53) & 5.152 & 13.608 & $6.52 \mathrm{E}-18$ \\
\hline \multirow[t]{24}{*}{ NFIB } & \multirow[t]{3}{*}{ TCGA } & \multirow[t]{3}{*}{ Breast (61) } & Invasive Ductal Breast Carcinoma (389) & -6.159 & -27.478 & $6.59 \mathrm{E}-80$ \\
\hline & & & Invasive Breast Carcinoma (76) & -4.54 & -13.706 & $5.59 \mathrm{E}-25$ \\
\hline & & & Invasive Lobular Breast Carcinoma (36) & -4.361 & -9.378 & $2.28 \mathrm{E}-12$ \\
\hline & \multirow[t]{7}{*}{ Curtis } & \multirow[t]{7}{*}{ Breast (144) } & Invasive Ductal Breast Carcinoma $(1,556)$ & -3.689 & -37.562 & 7.71E-116 \\
\hline & & & \begin{tabular}{|l|} 
Invasive Lobular Breast Carcinoma (148) \\
\end{tabular} & -2.675 & -16.623 & $1.54 \mathrm{E}-41$ \\
\hline & & & Invasive Ductal and Invasive Lobular Breast Carcinoma (90) & -3.334 & -14.802 & 1.13E-28 \\
\hline & & & Ductal Breast Carcinoma in Situ (10) & -2.275 & -4.665 & $5.10 \mathrm{E}-04$ \\
\hline & & & \begin{tabular}{|l|} 
Mucinous Breast Carcinoma (46) \\
\end{tabular} & -5.352 & -13.363 & $1.95 \mathrm{E}-18$ \\
\hline & & & Tubular Breast Carcinoma (67) & -3.096 & -13.05 & $4.36 \mathrm{E}-22$ \\
\hline & & & Breast Phyllodes Tumor (5) & -2.34 & -3.955 & 0.008 \\
\hline & \multirow[t]{4}{*}{ Ma 4} & \multirow[t]{4}{*}{ Breast (14) } & Invasive Ductal Breast Carcinoma Stroma (9) & -3.974 & -5.874 & $5.06 \mathrm{E}-06$ \\
\hline & & & Ductal Breast Carcinoma in Situ Epithelial (9) & -4.958 & -8.387 & $9.82 \mathrm{E}-08$ \\
\hline & & & Invasive Ductal Breast Carcinoma Epithelia(9) & -2.272 & -7.553 & 4.99E-07 \\
\hline & & & Ductal Breast Carcinoma in Situ Stroma (9) & -2.008 & -4.236 & 1.60E-04 \\
\hline & \multirow[t]{2}{*}{ Zhao } & Breast (3) & Invasive Ductal Breast Carcinoma (37) & -4.418 & -8.645 & $1.20 \mathrm{E}-08$ \\
\hline & & & Lobular Breast Carcinoma (21) & -3.452 & -7.496 & 7.44E-07 \\
\hline & \multirow[t]{2}{*}{ Turashvili } & Ductal Breast Cell (10) & \multirow{2}{*}{ Invasive Lobular Breast Carcinoma (5) } & \multirow[t]{2}{*}{-8.342} & \multirow[t]{2}{*}{-8.342} & \multirow[t]{2}{*}{0.002} \\
\hline & & bular Breast Cell (10) & & & & \\
\hline & Sorlie & Breast (4) & Ductal Breast Carcinoma (63) & -2.554 & -5.64 & $2.42 \mathrm{E}-04$ \\
\hline & Richardson & Breast (7) & Ductal Breast Carcinoma (40) & -4.237 & -7.552 & $9.00 \mathrm{E}-10$ \\
\hline & Sorlie 2 & Breast (4) & Ductal Breast Carcinoma (86) & -2.501 & -5.143 & 0.002 \\
\hline & Perou & Breast (3) & Ductal Breast Carcinoma (35) & -2.535 & -4.175 & 0.005 \\
\hline & Gluck & Breast (4) & Invasive Breast Carcinoma (154) & -2.041 & -7.529 & $2.46 \mathrm{E}-05$ \\
\hline & Finak & Breast (6) & Invasive Breast Carcinoma (53) & 8.451 & 13.331 & $1.59 \mathrm{E}-13$ \\
\hline \multirow[t]{2}{*}{ NFIC } & Richardson & Breast $(7)$ & Ductal Breast Carcinoma (40) & -2.196 & -5.431 & 6.11E-06 \\
\hline & Sorlie 2 & Breast (4) & Lobular Breast Carcinoma (6) & -2.029 & -3.852 & 0.003 \\
\hline \multirow[t]{8}{*}{ NFIX } & \multirow[t]{2}{*}{ Curtis } & \multirow[t]{2}{*}{ Breast (144) } & Invasive Ductal Breast Carcinoma $(1,556)$ & -2.138 & -27.969 & $2.43 \mathrm{E}-104$ \\
\hline & & & Invasive Ductal and Invasive Lobular Breast Carcinoma (90) & -2.121 & -12.042 & $5.06 \mathrm{E}-22$ \\
\hline & Sorlie & Breast (4) & Ductal Breast Carcinoma (63) & -2.417 & -6.071 & 5.29E-05 \\
\hline & Perou & Breast (3) & Ductal Breast Carcinoma (36) & -2.292 & -5.401 & $6.13 \mathrm{E}-04$ \\
\hline & Sorlie 2 & Breast (4) & Ductal Breast Carcinoma (92) & -2.319 & -5.898 & 4.21E-04 \\
\hline & Zhao & Breast (3) & Invasive Ductal Breast Carcinoma (34) & -2.214 & -6.293 & 2.85E-06 \\
\hline & Karnoub & Breast (15) & Invasive Ductal Breast Carcinoma Stroma(7) & -2.012 & -3.55 & 0.001 \\
\hline & Gluck & Breast (4) & Invasive Breast Carcinoma (154) & -2.573 & -7 & $5.94 \mathrm{E}-04$ \\
\hline
\end{tabular}

2 Abbreviations: NFI, Nuclear factor I; TCGA, The Cancer Genome Atlas. 
Table 2 (on next page)

Correlation of NFIs with survival outcomes in breast cancer patients 
Table 2 Correlation of NFIs with survival outcomes in breast cancer patients

\begin{tabular}{|c|c|c|c|c|c|c|c|}
\hline Gene & Affymetrix ID & Survival outcome & NO.of cases & Cut-off value & HR & $95 \% \mathrm{Cl}$ & p-value \\
\hline \multirow[t]{4}{*}{ NFIA } & 226806_s_at & OS & 1402 & 1490 & 0.9 & $0.65-1.22$ & 0.49 \\
\hline & & RFS & 3951 & 1519 & 0.72 & $0.61-0.84$ & $<0.001$ \\
\hline & & DMFS & 1746 & 1484 & 0.94 & $0.68-1.3$ & 0.72 \\
\hline & & PPS & 414 & 1488 & 1.03 & $0.72-1.47$ & 0.88 \\
\hline \multirow[t]{4}{*}{ NFIB } & 213029_at & OS & 1402 & 1292 & 0.94 & $0.76-1.16$ & 0.56 \\
\hline & & RFS & 3951 & 1216 & 1.1 & $0.99-1.23$ & 0.086 \\
\hline & & DMFS & 1746 & 1226 & 1.09 & $0.9-1.32$ & 0.39 \\
\hline & & PPS & 414 & 1277 & 1.2 & $0.94-1.53$ & 0.14 \\
\hline \multirow[t]{4}{*}{ NFIC } & 226377_at & OS & 1402 & 690 & 0.79 & $0.58-1.08$ & 0.14 \\
\hline & & RFS & 3951 & 1155 & 0.84 & $0.72-0.98$ & 0.025 \\
\hline & & DMFS & 1746 & 1005 & 0.85 & $0.61-1.17$ & 0.31 \\
\hline & & PPS & 414 & 657 & 1.36 & $0.96-1.94$ & 0.086 \\
\hline \multirow[t]{4}{*}{ NFIX } & 227400_at & OS & 1402 & 585 & 0.71 & $0.52-0.97$ & 0.033 \\
\hline & & RFS & 3951 & 723 & 0.82 & $0.7-0.95$ & 0.0098 \\
\hline & & DMFS & 1746 & 684 & 0.96 & $0.7-1.33$ & 0.81 \\
\hline & & PPS & 414 & 539 & 0.92 & $0.65-1.32$ & 0.67 \\
\hline
\end{tabular}

2 Abbreviations: HR, hazard ratio; CI, confidence interval; OS, overall survival; RFS,

3 progression free survival; DMFS, distant metastasis free survival; PPS, post progression survival. 
Table 3(on next page)

Datasets of the NFI family in lung cancer (ONCOMINE database) 
Table 3 Datasets of the NFI family in lung cancer (ONCOMINE database)

\begin{tabular}{|c|c|c|c|c|c|c|}
\hline Gene & Dataset & Normaln cases』 & Tumorn cases & Fold change & t-test & p-value \\
\hline \multirow[t]{8}{*}{ NFIA } & Okayama & Lung! 20! & Lung Adenocarcinoma (226) & -2.25 & -15.234 & $1.13 \mathrm{E}-25$ \\
\hline & \multirow[t]{6}{*}{ Garber } & Lung[ 5] & Lung Adenocarcinoma (40) & -2.404 & -7.113 & 3.60E-06 \\
\hline & & \begin{tabular}{|l|l} 
Lung] 5! & \\
\end{tabular} & Large Cell Lung Carcinoma (4) & -2.498 & -5.019 & 0.002 \\
\hline & & \begin{tabular}{|l|l|} 
Lung 5[ \\
\end{tabular} & Small Cell Lung Carcinoma (4) & -2.657 & -5.127 & 0.002 \\
\hline & & \begin{tabular}{|l|l|} 
Lungl 5] & \\
\end{tabular} & Squamous Cell Lung Carcinoma (13) & -2.325 & -3.934 & 5.77E-04 \\
\hline & & Lung] 5[ & Small Cell Lung Carcinoma (4) & 3.708 & 4.848 & $7.78 \mathrm{E}-04$ \\
\hline & & Lung! 5! & Squamous Cell Lung Carcinoma (13) & 4.124 & 4.747 & 2.93E-04 \\
\hline & Hou & Lung[ 65! & Lung Adenocarcinoma (45) & -2.564 & -7.923 & $4.56 \mathrm{E}-11$ \\
\hline \multirow[t]{7}{*}{ NFIB } & Stearman & Lung (19) & Lung Adenocarcinoma (20) & -2.163 & -8.091 & 2.63E-09 \\
\hline & \multirow[t]{3}{*}{ Bhattacharjee } & \multirow[t]{3}{*}{ Lung (17) } & Lung Carcinoid Tumor (20) & -20.662 & -8.304 & $6.88 \mathrm{E}-10$ \\
\hline & & & Lung Adenocarcinoma (132) & -4.608 & -5.259 & $2.21 \mathrm{E}-05$ \\
\hline & & & Squamous Cell Lung Carcinoma (21) & -3.994 & -3.58 & $5.13 \mathrm{E}-04$ \\
\hline & Garber & Lung (5) & Large Cell Lung Carcinoma (4) & -2.177 & -4.062 & 0.008 \\
\hline & Wachi & Lung (5) & Squamous Cell Lung Carcinoma (5) & -2.432 & -3.578 & 0.004 \\
\hline & Hou & Lung (65) & Squamous Cell Lung Carcinoma (27) & -2.422 & -9.841 & $3.81 \mathrm{E}-12$ \\
\hline \multirow[t]{2}{*}{ NFIC } & \multirow[t]{2}{*}{ Bhattacharjee } & \multirow[t]{2}{*}{ Lung (17) } & Lung Adenocarcinoma (132) & -4.007 & -4.325 & $2.01 \mathrm{E}-04$ \\
\hline & & & Small Cell Lung Carcinoma (6) & -4.793 & -4.575 & 8.63E-05 \\
\hline NFIX & Garber & Lung (5) & Large Cell Lung Carcinoma (4) & -2.032 & -4.228 & 0.003 \\
\hline
\end{tabular}


Table 4 (on next page)

Correlation of NFIs with survival outcomes in lung cancer patients 
Table 4 Correlation of NFls with survival outcomes in lung cancer patients

\begin{tabular}{|c|c|c|c|c|c|c|c|}
\hline Gene & Affymetrix ID & Survival outcome & NO.of cases & Cut-off value & HR & $95 \% \mathrm{Cl}$ & p-value \\
\hline \multirow[t]{3}{*}{ NFIA } & 226806_s_at & OS & 1926 & 697 & 0.58 & $0.49-0.69$ & $<0.001$ \\
\hline & & FP & 982 & 981 & 0.69 & $0.53-0.9$ & 0.0069 \\
\hline & & PPS & 344 & 1015 & 0.59 & $0.38-0.91$ & 0.016 \\
\hline \multirow[t]{3}{*}{ NFIB } & 213029_at & OS & 1926 & 1014 & 0.69 & $0.61-0.78$ & $<0.001$ \\
\hline & & FP & 982 & 1179 & 0.9 & 0.74-1.09 & 0.28 \\
\hline & & PPS & 344 & 1237 & 0.66 & $0.52-0.86$ & 0.0015 \\
\hline \multirow[t]{3}{*}{ NFIC } & 226377_at & OS & 1926 & 439 & 0.91 & $0.77-1.08$ & 0.27 \\
\hline & & FP & 982 & 464 & 1.16 & $0.88-1.51$ & 0.29 \\
\hline & & PPS & 344 & 426 & 1.7 & \begin{tabular}{|l|}
$1.1-2.62$ \\
\end{tabular} & 0.016 \\
\hline \multirow[t]{3}{*}{ NFIX } & 227400_at & OS & 1926 & 339 & 0.97 & $0.82-1.14$ & 0.72 \\
\hline & & FP & 982 & 373 & 1.2 & $0.92-1.57$ & 0.18 \\
\hline & & PPS & 344 & 353 & 1.18 & $0.77-1.82$ & 0.44 \\
\hline
\end{tabular}

2 Abbreviations: HR, hazard ratio; CI, confidence interval; OS, overall survival; FP, first 3 progression; PPS, post progression survival. 


\section{Table 5 (on next page)}

Datasets of the NFI family in bladder cancer (ONCOMINE database) 
Table 5 Datasets of the NFI family in bladder cancer (ONCOMINE database)

\begin{tabular}{|c|c|c|c|c|c|c|}
\hline Gene & Dataset & Normal』 cases》 & 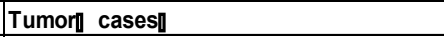 & Fold change & t-test & p-value \\
\hline \multirow[t]{2}{*}{ NFIA } & \multirow[t]{2}{*}{ Lee } & \multirow[t]{2}{*}{ Bladder Mucosa (68) } & Superficial Bladder Cancer (126) & -2.034 & -7.839 & $8.56 \mathrm{E}-13$ \\
\hline & & & Infiltrating Bladder Urothelial Carcinoma (62) & -2.02 & -5.127 & 5.30E-07 \\
\hline \multirow[t]{3}{*}{ NFIB } & \multirow{2}{*}{$\begin{array}{l}\text { Sanchez- } \\
\text { Carbayo } 2\end{array}$} & \multirow[t]{2}{*}{ Bladder (48) } & Infiltrating Bladder Urothelial Carcinoma (81) & -3.224 & -11.267 & $8.55 \mathrm{E}-21$ \\
\hline & & & Superficial Bladder Cancer (28) & -5.44 & -10.279 & $3.85 \mathrm{E}-13$ \\
\hline & Lee & Bladder Mucosa (68) & Superficial Bladder Cancer (126) & -2.817 & -8.17 & 9.13E-14 \\
\hline \multirow[t]{3}{*}{ NFIC } & \multirow[t]{2}{*}{ Blaveri 2} & \multirow[t]{2}{*}{ Bladder (3) } & Superficial Bladder Cancer (26) & -3.478 & -16.225 & $2.22 \mathrm{E}-15$ \\
\hline & & & Infiltrating Bladder Urothelial Carcinoma (53) & -2.182 & -13.966 & $7.22 \mathrm{E}-20$ \\
\hline & \begin{tabular}{|l|} 
Sanchez- \\
Carbayo 2
\end{tabular} & Bladder (48) & Superficial Bladder Cancer (28) & -3.362 & -5.985 & 8.05E-08 \\
\hline NFIX & Lee & Bladder Mucosa (68) & Superficial Bladder Cancer (126) & -2.417 & -8.103 & 9.27E-14 \\
\hline
\end{tabular}


Table 6(on next page)

Correlation of NFIs with survival outcomes in bladder cancer patients 
Table 6 Correlation of NFIs with survival outcomes in bladder cancer patients

\begin{tabular}{|l|l|l|l|l|l|l|l|}
\hline Gene & RNAseq ID & Survival outcome & NO.of cases & Cut-off value & HR & $\mathbf{9 5 \%} \mathbf{~ C l}$ & $\mathbf{p}$-value \\
\hline NFIA & 4774 & OS & 404 & 662 & 1.72 & $1.28-2.31$ & $<0.001$ \\
\hline & & RFS & 187 & 804 & 0.54 & $0.22-1.31$ & 0.16 \\
\hline NFIB & 4781 & OS & 404 & 767 & 0.87 & $0.65-1.16$ & 0.34 \\
\hline & & RFS & 187 & 591 & 2.19 & $0.98-4.9$ & 0.051 \\
\hline NFIC & 4782 & OS & 404 & 2028 & 1.59 & $1.18-2.13$ & 0.0018 \\
\hline & & RFS & 187 & 1858 & 1.73 & $0.84-4.9$ & 0.13 \\
\hline NFIX & 4784 & OS & 404 & 1176 & 1.36 & $1.01-1.83$ & 0.045 \\
\hline & & RFS & 187 & 419 & 1.68 & $0.64-4.37$ & 0.29 \\
\hline
\end{tabular}

2 Abbreviations: HR, hazard ratio; CI, confidence interval; OS, overall survival; RFS, relapse free 3 survival. 
Table 7 (on next page)

Datasets of the NFI family in head-neck cancer (ONCOMINE database) 
Table 7 Datasets of the NFI family in head-neck cancer (ONCOMINE database)

\begin{tabular}{|c|c|c|c|c|c|c|}
\hline Gene & Dataset & Normaln casesn & Tumorn cases & Fold change & t-test & $p$-value \\
\hline \multirow[t]{3}{*}{ NFIA } & Ye Head-Neck & Normal(Tongue(12)) & Tongue Squamous Cell Carcinoma(26) & -3.296 & -7.117 & $2.53 \mathrm{E}-08$ \\
\hline & Pyeon Multi-cancer & $\begin{array}{l}\text { Normal(Cervix Uteri(8) Oral } \\
\text { Cavity(9) Palate(1) Tonsil(4)) }\end{array}$ & Tonsillar Carcinoma(6) & -2.285 & -4.799 & $3.09 \mathrm{E}-05$ \\
\hline & Sengupta Head-Neck & Normal(Nasopharynx(10)) & Nasopharyngeal Carcinoma(31) & -2.036 & -4.997 & $5.60 \mathrm{E}-05$ \\
\hline \multirow[t]{4}{*}{ NFIB } & Estilo Head-Neck & Normal(Tongue(26)) & Tongue Squamous Cell Carcinoma(31) & -3.388 & -8.191 & $3.28 \mathrm{E}-11$ \\
\hline & Ye Head-Neck & Normal(Tongue(12)) & Tongue Squamous Cell Carcinoma(26) & -2.984 & -3.941 & $1.91 \mathrm{E}-04$ \\
\hline & Cromer Head-Neck & Normal(Uvula(4)) & Head and Neck Squamous Cell Carcinoma(34) & -2.63 & -4.165 & $5.86 \mathrm{E}-04$ \\
\hline & FriersonHF Salivary-gland & Normal(Salivary Gland(6)) & Salivary Gland Adenoid Cystic Carcinoma(16) & 2.485 & 6.724 & $1.21 \mathrm{E}-06$ \\
\hline \multirow[t]{2}{*}{ NFIX } & Peng Head-Neck & Normal(Oral Cavity(22)) & Oral Cavity Squamous Cell Carcinoma(57) & -2.754 & -19.426 & 1.17E-31 \\
\hline & Estilo Head-Neck & Normal(Tongue(26)) & Tongue Squamous Cell Carcinoma(31) & -2.343 & -3.731 & $2.90 \mathrm{E}-04$ \\
\hline
\end{tabular}


Table 8(on next page)

Correlation of NFIs with survival outcomes in head-neck cancer patients 
Table 8 Correlation of NFls with survival outcomes in head-neck cancer patients

\begin{tabular}{|l|l|l|l|l|l|l|l|}
\hline Gene & RNAseq ID & Survival outcome & NO.of cases & Cut-off value & HR & $\mathbf{9 5 \%} \mathbf{~ C l}$ & $\mathbf{p}$-value \\
\hline NFIA & 4774 & OS & 499 & 838 & 0.6 & $0.45-0.81$ & $<0.001$ \\
\hline & & RFS & 124 & 827 & 0.53 & $0.24-1.17$ & 0.11 \\
\hline NFIB & 4781 & OS & 499 & 487 & 0.74 & $0.55-0.99$ & 0.043 \\
\hline & & RFS & 124 & 1288 & 0.56 & $0.21-1.47$ & 0.23 \\
\hline NFIC & 4782 & OS & 499 & 1705 & 0.64 & $0.48-0.85$ & 0.0019 \\
\hline & & RFS & 124 & 3021 & 0.64 & $0.24-1.7$ & 0.37 \\
\hline NFIX & 4784 & OS & 499 & 1959 & 0.76 & $0.57-1.02$ & 0.069 \\
\hline & & RFS & 124 & 1819 & 0.47 & $0.19-1.15$ & 0.091 \\
\hline
\end{tabular}

2 Abbreviations: HR, hazard ratio; CI, confidence interval; OS, overall survival; RFS, relapse free 3 survival. 
Table 9 (on next page)

Datasets of the NFI family in esophageal carcinoma (ONCOMINE database) 


\begin{tabular}{|c|c|c|c|c|c|c|}
\hline Table 9 & Datasets of the & $\mathrm{Fl} \mathrm{family} \mathrm{in} \mathrm{esophageal} \mathrm{carcinoma} \mathrm{(} 0$ & VCOMINE database) & & & \\
\hline Gene & Dataset & Normaln cases』 & Tumor』 cases』 & Fold change & t-test & p-value \\
\hline \multirow[t]{3}{*}{ NFIA } & Su Esophagus 2 & \begin{tabular}{|l} 
Normal(esophagus(51)) \\
\end{tabular} & Esophageal Squamous Cell Carcinoma(51) & -2.142 & -9.685 & $3.66 \mathrm{E}-16$ \\
\hline & \multirow[t]{2}{*}{ Kim Esophagus } & \multirow{2}{*}{ Normal(esophagus(28)) } & Esophageal Adenocarcinoma(75) & -2.465 & -9.118 & $4.98 \mathrm{E}-15$ \\
\hline & & & Barrett's Esophagus(15) & -2.171 & -7.186 & $6.82 \mathrm{E}-08$ \\
\hline \multirow[t]{4}{*}{ NFIX } & \multirow[t]{2}{*}{ Kim Esophagus } & \multirow[t]{2}{*}{ Normal(esophagus(28)) } & Esophageal Adenocarcinoma(75) & -4.387 & -10.777 & $9.43 \mathrm{E}-19$ \\
\hline & & & Barrett's Esophagus(15) & -3.31 & -9.268 & $1.01 \mathrm{E}-09$ \\
\hline & \multirow[t]{2}{*}{ Hao Esophagus } & Normal(Duodenum(13)Esophagus(15)) & Esophageal Adenocarcinoma(5) & 2.447 & 4.617 & 4.96E-05 \\
\hline & & Normal(Duodenum(11)Esophagus(13)) & Barrett's Esophagus(12) & 2.364 & 3.701 & 5.09E-04 \\
\hline
\end{tabular}




\section{Table $\mathbf{1 0}$ (on next page)}

Correlation of NFIs with survival outcomes in esophageal cancer patients

10a. Correlation of NFIs with survival outcomes in esophageal squamous cell carcinoma patients

10b. Correlation of NFIs with survival outcomes in esophageal adenocarcinoma patients 
Table 10a Correlation of NFls with survival outcomes in esophageal squamous cell carcinoma patients

\begin{tabular}{|l|l|l|l|l|l|l|l|}
\hline Gene & RNAseq ID & Survival outcome & NO.of cases & Cut-off value & HR & $\mathbf{9 5 \%}$ Cl & p-value \\
\hline NFIA & 4774 & OS & 81 & 2029 & 0.64 & $0.27-1.55$ & 0.32 \\
\hline & & RFS & 54 & 1211 & 0.57 & $0.22-1.49$ & 0.25 \\
\hline NFIB & 4781 & OS & 81 & 2102 & 0.51 & $0.21-1.24$ & 0.13 \\
\hline & & RFS & 54 & 2422 & 0.31 & $0.09-1.1$ & 0.056 \\
\hline NFIC & 4782 & OS & 81 & 7712 & 0.45 & $0.18-1.13$ & 0.08 \\
\hline & & RFS & 54 & 9377 & 1.45 & $0.53-3.91$ & 0.47 \\
\hline NFIX & 4784 & OS & 81 & 4135 & 0.72 & $0.3-1.73$ & 0.46 \\
\hline & & RFS & 54 & 4135 & 0.35 & $0.1-1.24$ & 0.09 \\
\hline
\end{tabular}

Table 10b Correlation of NFIs with survival outcomes in esophageal adenocarcinoma patients

\begin{tabular}{|l|l|l|l|l|l|l|l|}
\hline Gene & RNAseq ID & Survival outcome & NO.of cases & Cut-off value & HR & $\mathbf{9 5 \%} \mathbf{C l}$ & $\mathbf{p}$-value \\
\hline NFIA & 4774 & OS & 80 & 2000 & 0.6 & $0.31-1.15$ & 0.12 \\
\hline & & RFS & 19 & 2161 & 6.57 & $0.66-65.46$ & 0.068 \\
\hline NFIB & 4781 & OS & 80 & 2571 & 1.46 & $0.76-2.79$ & 0.25 \\
\hline & & RFS & 19 & 4327 & 3.03 & $0.42-21.68$ & 0.25 \\
\hline NFIC & 4782 & OS & 80 & 3741 & 0.44 & $0.22-0.9$ & 0.02 \\
\hline & & RFS & 19 & 3579 & 271493742 & $0-$ Inf & 0.28 \\
\hline NFIX & 4784 & OS & 80 & 3353 & 0.33 & $0.16-0.68$ & 0.0017 \\
\hline & & RFS & 19 & 3373 & 0 & $0-$ Inf & 0.018 \\
\hline
\end{tabular}

3 Abbreviations: $\mathrm{HR}$, hazard ratio; CI, confidence interval; OS, overall survival; RFS, relapse free 4 survival. 


\section{Table 11 (on next page)}

Datasets of the NFI family in kidney cancer (ONCOMINE database) 
Table 11 Datasets of the NFI family in kidney cancer (ONCOMINE database)

\begin{tabular}{|c|c|c|c|c|c|c|}
\hline Gene & Dataset & Normaln cases $\|$ & Tumorn cases』 & Fold change & t-test & $p$-value \\
\hline NFIA & Higgins Renal & Normal(Kidney(3)) & Clear Cell Sarcoma of the Kidney(25) & 2.061 & 4.058 & 0.0005 \\
\hline \multirow[t]{5}{*}{ NFIB } & Cutcliffe Renal & Normal(Fetal Kidney(3)) & Renal Wilms Tumor(18) & -5.72 & -7.098 & $5.18 \mathrm{E}-07$ \\
\hline & \multirow[t]{2}{*}{ Yusenko Renal } & \multirow[t]{2}{*}{ Normal(Fetal Kidney(2) Kidney(3)) } & Chromophobe Renal Cell Carcinoma(4) & -2.281 & -4.333 & 0.002 \\
\hline & & & Renal Oncocytoma(4) & -3.229 & -4.26 & 0.003 \\
\hline & Cutcliffe Renal & Normall(Fetal Kidney(3)) & Clear Cell Sarcoma of the Kidney(14) & 3.771 & 15.494 & 1.27E-09 \\
\hline & \begin{tabular}{|l} 
Jones Renal \\
\end{tabular} & Normal(Kidney(23)) & Papillary Renal Cell Carcinoma(11) & 2.661 & 6.739 & $5.14 \mathrm{E}-07$ \\
\hline
\end{tabular}




\section{Table 12 (on next page)}

Correlation of NFIs with survival outcomes in kidney cancer patients

12a.Correlation of NFIs with survival outcomes in kidney renal clear cell carcinoma patients.

12b.Correlation of NFIs with survival outcomes in kidney renal papillary cell carcinoma patients 
Table 12a Correlation of NFls with survival outcomes in kidney renal clear cell carcinoma patients

\begin{tabular}{|l|l|l|l|l|l|l|l|}
\hline Gene & RNAseq ID & Survival outcome & NO.of cases & Cut-off value & HR & $\mathbf{9 5 \%}$ Cl & p-value \\
\hline NFIA & 4774 & OS & 530 & 1758 & 0.5 & $0.37-0.68$ & $<0.001$ \\
\hline & & RFS & 117 & 1865 & 3 E+08 & $0-$ Inf & 0.017 \\
\hline NFIB & 4781 & OS & 530 & 3585 & 0.46 & $0.33-0.63$ & $<0.001$ \\
\hline & & RFS & 117 & 2646 & 4.62 & $0.61-35.15$ & 0.1 \\
\hline NFIC & 4782 & OS & 530 & 3627 & 0.73 & $0.54-0.98$ & 0.036 \\
\hline & & RFS & 117 & 3868 & 2.47 & $0.69-8.89$ & 0.15 \\
\hline NFIX & 4784 & OS & 530 & 1668 & 0.66 & $0.49-0.88$ & 0.0054 \\
\hline & & RFS & 117 & 1711 & 10.49 & $1.38-80.04$ & 0.0048 \\
\hline
\end{tabular}

Table 12b Correlation of NFIs with survival outcomes in kidney renal papillary cell carcinoma patients

\begin{tabular}{|l|l|l|l|l|l|l|l|}
\hline Gene & RNAseq ID & Survival outcome & NO.of cases & Cut-off value & HR & $\mathbf{9 5 \%} \mathbf{~ C I}$ & $\mathbf{p}$-value \\
\hline NFIA & 4774 & OS & 287 & 1332 & 0.34 & $0.19-0.61$ & $<0.001$ \\
\hline & & RFS & 183 & 1290 & 0.55 & $0.25-1.19$ & 0.13 \\
\hline NFIB & 4781 & OS & 287 & 2122 & 0.29 & $0.16-0.55$ & $<0.001$ \\
\hline & & RFS & 183 & 2149 & 0.36 & $0.17-0.77$ & 0.006 \\
\hline NFIC & 4782 & OS & 287 & 2721 & 0.62 & $0.34-1.13$ & 0.11 \\
\hline & & RFS & 183 & 3808 & 0.59 & $0.24-1.48$ & 0.26 \\
\hline NFIX & 4784 & OS & 287 & 1268 & 2.28 & $1.26-4.13$ & 0.0051 \\
\hline & & RFS & 183 & 1219 & 1.63 & $0.73-3.67$ & 0.23 \\
\hline
\end{tabular}

3 Abbreviations: $\mathrm{HR}$, hazard ratio; CI, confidence interval; OS, overall survival; RFS, relapse free 4 survival. 